Federal Reserve Bank of Dallas

Globalization and Monetary Policy Institute

Working Paper No. 6

http://www.dallasfed.org/assets/documents/institute/wpapers/2008/0006.pdf

\title{
Driving Forces of the Canadian Economy: An Accounting Exercise ${ }^{*}$
}

\author{
Simona E. Cociuba \\ Federal Reserve Bank of Dallas \\ Alexander Ueberfeldt \\ Bank of Canada
}

March 2008

\begin{abstract}
This paper analyses the Canadian economy for the post 1960 period. It uses an accounting procedure developed in Chari, Kehoe, and McGrattan (2006). The procedure identifies accounting factors that help align the predictions of the neoclassical growth model with macroeconomic variables observed in the data. The paper finds that total factor productivity and the consumption-leisure trade-off - the productivity and labor factors-are key to understanding the changes in output, labor supply and labor productivity observed in the Canadian economy. The paper performs a decomposition of the labor factor for Canada and the United States. It finds that the decline in the gender wage gap is a major driving force of the decrease in the labor market distortions. Moreover, the milder reduction in the labor market distortions observed in Canada, compared to the US, is due to a relative increase in effective labor taxes in Canada.
\end{abstract}

JEL codes: E23, E24, E60, J21

\footnotetext{
* Simona Cociuba, Research Department, Federal Reserve Bank of Dallas, 2200 N. Pearl Street, Dallas, TX 75201. simona.cociuba@dal.frb.org. Ueberfeldt, Research Department, 234 Wellington Street, Ottawa, Ontario K1A 0G9. aueberfeldt@bankofcanada.ca. We thank Richard Dion, Sharon Kozicki, Malik Shukayev and Mark Wynne for comments and suggestions. We thank Amanda Armstrong, Andrew Au, Sarah Howcroft, and Robert Kovac for excellent research assistance. The views in this paper are those of the authors and do not necessarily reflect the views of the Bank of Canada, the Federal Reserve Bank of Dallas or the Federal Reserve System.
} 


\section{Introduction}

The 1960s and 1970s were decades of good growth for Canada. Output per working-age person grew on average by 2.5 percent per year. Growth slowed down considerably starting in the 1980s, to an average rate of about 1.6 percent per year. Moreover, since 1961, Canadian output per working-age person has been on average 21 percent below that of the United States, its geographic neighbor and largest trading partner.

This paper addresses two questions. First, what accounts for the movements of output per working-age-person in Canada from 1961 to 2005? We give particular emphasis to the growth slowdown period. Second, what are the key elements that lead to differences in output per workingage person between the U.S. and the Canadian economy? To answer these questions we employ an accounting procedure developed in Chari, Kehoe, and McGrattan (2002,2006). We find two factors to be key to answer these questions. The first is a productivity factor (Solow residual or total factor productivity). A decline in the productivity factor's growth is the main driver of the growth slowdown in Canada. A comparison with the U.S. reveals that both countries experienced a similar growth slowdown in the productivity factor and that a part of the U.S.-Canada difference in output per working-age person is due to level differences in total factor productivity (TFP). The second factor of importance alters the decision of households between working in the market place and consuming. We call this the labor factor. Canada and the U.S. display very different patterns of the labor factor. A counterfactual experiment reveals that Canada would be able to considerably narrow the output differences with the U.S., if it reduced distortions underlying the labor factor similar to the U.S. We perform a decomposition of the labor factors which suggests that effective labor tax differences between Canada and the U.S. are a main source of the labor factor differences between the two countries. A small role is also played by cross-country differences in the gender wage gap.

In this paper, we use the methodology of Chari, Kehoe, and McGrattan (2006, henceforth CKM) to analyze the Canadian economy. This procedure allows researchers to identify accounting factors that help align the predictions of the neoclassical growth model with key observed data for macroeconomic variables. The procedure is particularly useful in determining which margins were distorted and to what extent the factors account for periods of economic downturns. The CKM methodology is applied to a standard neoclassical growth model economy. We use the equilibrium conditions of the calibrated model to measure four factors (productivity, labor, investment and government). Taking the factors as given we compute the optimal decision rules of households 
and firms. A comparison of the optimal decisions under various combinations of factors allows us to evaluate the importance of the respective factor for output, labor supply, investment, and so on. Since by construction all the factors combined account for all the variations in the data, this procedure is tantamount to an accounting exercise. Moreover, the relative importance of each factor provides valuable insight into the class of models that seem most promising to understand the macro fluctuations observed in the data.

As mentioned previously, we find that two factors are key in accounting for the movements of output per working-age-person and labor supply in Canada since 1961: the productivity factor and the labor factor. Similar findings for particular periods and other countries exist in the literature. CKM find that labor and productivity factors account for the U.S. and Canadian Great Depressions, and Ahearne, Kydland and Wynne (2006) find that the same two factors account for Ireland's depression in the 1980s. The importance of the labor factor for the 1980s depression in the United Kingdom was recently stressed in Kersting (2008). ${ }^{1}$

Regarding the Canadian growth slowdown period starting in the 1980s, we find that the productivity factor is the main source of the slowdown. To put this finding into perspective we compare Canada to the United States. The United States is a good benchmark for Canada since it is its biggest trading partner and it was the technology leader throughout the period in question. ${ }^{2}$ From this comparison, we discover that the decline in the productivity factor's growth in Canada is not extraordinary but rather in line with what was observed in the United States.

This brings us to our second question related to the sources of the U.S. - Canada output per working-age person differences. Our first finding is that part of the differences in output per workingage person between Canada and the U.S. can be attributed to level differences in the productivity factor; on average since 1961 Canadian TFP is about $85 \%$ of the U.S. level. Our second finding is that an important difference between Canada and the United States is in the labor factor. While in the U.S. the distortions underlying the labor factor have declined considerably since the 1980s, in Canada these distortions have remained high, suggesting an opportunity for Canada to increase its labor supply, output and private consumption by reducing these distortions in a similar fashion as the United States. We perform a counterfactual experiment for Canada, in which we let the growth

\footnotetext{
${ }^{1}$ The methodology has been used to analyze other countries as well. Chakraborty (2005) examines the Japanese economy and its lost decade during the 1990s. Cociuba (2007) analyzes the German economy since 1991, with special emphasis on the East-West German income differences.

${ }^{2}$ Our measure of technology leadership is the level of TFP and here the United States were the undisputed leader even in the period of Japan's rapid GDP growth.
} 
in the Canadian labor factor be the same as in the U.S., and keep the other accounting factors as measured from Canadian data. We find that in this experiment growth in output per working-age person per year would have been 0.6 percent higher since the 1980s, allowing Canada to eliminate about half the gap with the U.S. and be only 10 percent below the U.S. by 2005 .

From here on, we focus our attention on the labor factor differences, since there exists an extensive literature that analyzes the productivity factor in Canada as well as the Canadian - U.S. level differences in the productivity factor. ${ }^{3}$ Our guiding question is: What are the main sources of the widening gap in the labor factors between the two countries? Our approach to this question is a decomposition exercise as follows. We augment the standard model used so far to include three features: time varying labor income taxes, time varying labor income shares and female and male wage differentials. We show that this model is equivalent to the model used in the accounting exercise, and hence we are able to derive an equation that decomposes the labor factor into the three features mentioned above and a residual.

The three features we incorporate in our model have been suggested in the literature as potentially important for the movement of the labor income factor. Effective labor income taxes have been suggested by Prescott (2004), a time varying income share has been derived as an implication of capital utilization in Hansen and Prescott (2005), and Jones et al. (2003) show that gender wage discrimination along the lines of Goldin (1992) and the lifting of the 'glass ceiling' for women can be reduced to the labor factor. We find that the decrease in the male-female wage differential is a particularly important contributor to the overall decline in the labor market distortions in both economies. These three components together account for 57 percent of the changes in the labor factor in the case of the United States from 1980 to 2005. For Canada our decomposition is not able to account for much of the decrease in the labor factor distortions. The reduction in labor distortions associated with the fall in the gender wage gap observed in Canada is almost entirely wiped out by increased effective labor taxes and a decreased labor income share. Performing a counterfactual experiment in which we replace the various factors for Canada with their respective counterpart from the United States, we find that our decomposition is able to account for almost all of the widening gap in the labor factor between Canada and the United States. The predominant factor

\footnotetext{
${ }^{3}$ To mention a few papers: Lee and Tang (2000) and Rao et al. (2004) consider the industry dimension of the productivity factor gap; Rao et al. (2006) highlight among other possible cross country differences the importance of machinery and equipment and trade openness; Tang and Wang (2005) focus on the manufacturing sector and emphasize product market competition and skill shortages as productivity depressants. A collection of multiple studies focusing on the importance of information technology is provided in Jorgensen (2004).
} 
for the cross country difference is the effective labor income tax. A minor but not unimportant role falls onto the cross country differences in the gender wage gap.

The paper is organized as follows. In Section 2, we present the standard neoclassical growth model and the measurement of the accounting factors. We present the findings for the Canadian economy in Section 3. In Section 4, we present a model with labor market distortions that enables us to decompose the labor factor. We conclude with Section 5.

\section{Accounting Exercise}

In this section we review the CKM accounting methodology. We start with the presentation of the model economy. We then discuss the measurement of the accounting factors and their economic interpretations.

\subsection{Benchmark Economy}

The model economy is a one sector neoclassical growth model. The economy has four exogenous factors: the productivity factor, $A_{t}$, the labor factor, $1-\tau_{l, t}$, the investment factor, $1 /\left(1+\tau_{x, t}\right)$, and the government factor, $g_{t}$.

The representative consumer chooses sequences of per working-age-person consumption, $c_{t}$, per working-age-person investment, $x_{t}$, and per working-age-person labor, $l_{t}$, to maximize:

$$
\begin{aligned}
P(H H): & \max \sum_{t=0}^{\infty} \beta^{t} u\left(c_{t}, l_{t}\right) N_{t} \\
\text { subject to } \quad & c_{t}+\left(1+\tau_{x, t}\right) x_{t} \leq\left(1-\tau_{l, t}\right) w_{t} l_{t}+r_{t} k_{t}+T_{t} \\
& \frac{N_{t+1}}{N_{t}} k_{t+1} \leq x_{t}+(1-\delta) k_{t} \\
& k_{0} \text { given }
\end{aligned}
$$

where $k_{t}$ denotes the beginning of period per working-age-person capital stock, $r_{t}$ is the rental rate of capital, $w_{t}$ is the wage rate and $T_{t}$ represents per working-age-person lump-sum transfers. The working-age population at time $t$ is given by $N_{t}$ and it grows at rate $\eta$, hence $N_{t+1}=(1+\eta) N_{t}$.

The production technology is given by $F\left(K_{t}, z_{t} L_{t}\right)$ which is homogenous of degree one in the two inputs $K_{t}$ and $z_{t} L_{t}$. There is labor augmenting technical progress in the economy at a constant yearly rate of $\gamma-1$. Hence, $z_{t}=\hat{z}_{t} \gamma^{t}$, where the growth factor, $\gamma^{t}$, denotes the constant technological progress and $\hat{z}_{t}$ represents deviations from trend growth. Note that given the functional form $F\left(K_{t}, z_{t} L_{t}\right)=K_{t}^{\theta}\left(z_{t} L_{t}\right)^{1-\theta}$, the production function can be written as $F\left(K_{t}, z_{t} L_{t}\right)=$ $A_{t} K_{t}^{\theta}\left(\gamma^{t} L_{t}\right)^{1-\theta}$, where $A_{t} \equiv \hat{z}_{t}^{1-\theta}$. The representative firm's problem is to maximize profits given 
by:

$$
P(F): \max F\left(K_{t}, z_{t} L_{t}\right)-r_{t} K_{t}-w_{t} L_{t}
$$

Finally, the government balances its budget every period:

$$
\left(g_{t}+T_{t}\right) N_{t}=\left(\tau_{x, t} x_{t}+\tau_{l, t} w_{t} l_{t}\right) N_{t}
$$

Note that in the model, $\tau_{x, t}$ and $\tau_{l, t}$ look like taxes (or subsidies) on investment and labor income, respectively. However in the accounting procedure $\tau_{x, t}$ and $\tau_{l, t}$ could also stand in for factors other than taxes. Hence, we refer to $1-\tau_{l, t}, 1 /\left(1+\tau_{x, t}\right)$ and the other two factors as accounting factors.

\section{Characterization of Equilibrium}

Definition 1. A competitive equilibrium is an allocation $\left(c_{t}, x_{t}, k_{t}, l_{t}, K_{t}, L_{t}\right)_{t=0}^{\infty}$ and a price system $\left(r_{t}, w_{t}\right)_{t=0}^{\infty}$ such that:

1. Given the exogenous sequences $\left(\tau_{l, t}, \tau_{x, t}, g_{t}\right)_{t=0}^{\infty}$ and the prices, $\left(c_{t}, x_{t}, k_{t}, l_{t}\right)_{t=0}^{\infty}$ solves the household problem, $P(H H)$

2. Given the prices, $\left(K_{t}, L_{t}\right)_{t=0}^{\infty}$ solves the firm's problem, $P(F)$

3. The resource constraints are satisfied for all $t$ :

$$
\begin{aligned}
N_{t}\left(c_{t}+x_{t}+g_{t}\right) & \leq F\left(K_{t}, z_{t} L_{t}\right) \\
K_{t} & \leq N_{t} k_{t} \\
L_{t} & \leq N_{t} l_{t}
\end{aligned}
$$

We use the following functional forms for our analysis:

$$
\begin{aligned}
u\left(c_{t}, l_{t}\right) & =\frac{\left(c_{t}\left(1-l_{t}\right)^{\alpha}\right)^{1-\sigma}-1}{1-\sigma} \\
F\left(K_{t}, z_{t} L_{t}\right) & =K_{t}^{\theta}\left(z_{t} L_{t}\right)^{1-\theta}
\end{aligned}
$$

We detrend all variables that grow over time with the technology trend and indicate them with hats (e.g. detrended consumption will be $\hat{c}_{t}=c_{t} / \gamma^{t}$ ). The equilibrium is characterized by the 
following first order conditions (for derivation see section A.1):

$$
\begin{aligned}
\frac{u_{2}\left(\hat{c}_{t}, l_{t}\right)}{u_{1}\left(\hat{c}_{t}, l_{t}\right)} & =\hat{z}_{t} F_{2}\left(\hat{k}_{t}, \hat{z}_{t} l_{t}\right)\left(1-\tau_{l, t}\right) \\
\left(1+\tau_{x, t}\right) \frac{u_{1}\left(\hat{c}_{t}, l_{t}\right)}{u_{1}\left(\hat{c}_{t+1}, l_{t+1}\right)} & =\beta \gamma^{-\sigma}\left[(1-\delta)\left(1+\tau_{x, t+1}\right)+F_{1}\left(\hat{k}_{t+1}, \hat{z}_{t+1} l_{t+1}\right)\right] \\
\hat{c}_{t}+\hat{x}_{t}+\hat{g}_{t} & =F\left(\hat{k}_{t}, \hat{z}_{t} l_{t}\right) \\
\eta \gamma \hat{k}_{t+1} & =\hat{x}_{t}+(1-\delta) \hat{k}_{t} \\
\lim _{t \rightarrow \infty}\left(\beta \eta \gamma^{1-\sigma}\right)^{t} u_{1}\left(\hat{c}_{t}, l_{t}\right) \hat{k}_{t+1} & =0 .
\end{aligned}
$$

\subsection{Measurement of the Accounting Factors}

Given parameters, and data on $\hat{c}_{t}, \hat{x}_{t}, \hat{g}_{t}, \hat{y}_{t}, l_{t}$, and $\hat{k}_{t}$ we use equilibrium conditions to measure the factors.

- The productivity factor, $A_{t}$, is determined as:

$$
A_{t} \equiv \hat{z}_{t}^{1-\theta}=\frac{\hat{y}_{t}}{\hat{k}_{t}^{\theta} l_{t}^{1-\theta}}
$$

- The labor factor, $1-\tau_{l, t}$, is determined as the solution to equation (1):

$$
1-\tau_{l, t}=\frac{u_{2}\left(\hat{c}_{t}, l_{t}\right)}{u_{1}\left(\hat{c}_{t}, l_{t}\right)} \frac{1}{\hat{z}_{t} F_{2}\left(\hat{k}_{t}, \hat{z}_{t} l_{t}\right)}
$$

- To compute the investment factor, $1 /\left(1+\tau_{x, t}\right)$, we calculate $\tau_{x, t}$ as the solution to equation (2):

$$
\tau_{x, t+1}=(1-\delta)^{-1}\left(\frac{\left(1+\tau_{x, t}\right)}{\beta \gamma^{-\sigma}} \frac{u_{1}\left(\hat{c}_{t}, l_{t}\right)}{u_{1}\left(\hat{c}_{t+1}, l_{t+1}\right)}-F_{1}\left(\hat{k}_{t+1}, \hat{z}_{t+1} l_{t+1}\right)\right)-1 ; \quad \forall t=0, \ldots, T .
$$

- Finally, we determine the government consumption factor, $\hat{g}_{t}$ directly from data by adding government consumption and net exports. We then divide by the working-age population and detrend by the technology growth trend.

In the equations above, $\hat{c}_{t}, \hat{x}_{t}, \hat{g}_{t}, \hat{y}_{t}$, and $l_{t}$ are taken from data (See appendix A.4 for details on the sources of the data). Given lack of sufficient detail of data for the Canadian economy, we make two assumptions. First, we assume that government investment is not productive; that is, we treat government investment just like government consumption. Second, we assume consumer 
durables are consumption goods and not investment goods. As a result of these two assumptions, the capital stock for our economy consists only of the net private fixed assets and the stock of private inventories. ${ }^{4}$ We are confident that these assumptions on the data do not alter our qualitative findings. In fact we are able to show that similar results are obtained for the U.S. economy for different treatment of consumer durables or government consumption. ${ }^{5}$

We construct the capital stock, $\hat{k}_{t}$, using the perpetual inventory method. Given the 1961 capital stock which we identify as $k_{0}$ and using a fixed depreciation, we construct the capital stock series as follows:

$$
\gamma \eta \hat{k}_{t+1}=\hat{x}_{t}+(1-\delta) \hat{k}_{t}
$$

The parameters used in the accounting exercise are presented in Table 2. All the parameters, except for the population growth, are common across the two economies and are calibrated to the U.S. economy for the period $1961-2005$. We determine $\theta$ to match the share of capital income in total income, $\delta$ to match a ratio of depreciation to output of 9.7 percent and a capital-output ratio of 2.35. ${ }^{6}$ The technology growth, $\gamma$, is chosen to match the average growth in output per workingage person. The discount factor is chosen to match a rate of return on capital of 4.5 percent (i.e. $\beta=\gamma / 1.045)$. The utility parameters $\alpha$ and $\sigma$ are chosen following Cooley and Prescott (1995). Finally, the population growth rate is chosen to match the average growth rate of the population aged 16 to 64 years in each economy from 1961 to $2005 .^{7}$

\footnotetext{
${ }^{4}$ Cooley and Prescott (1995) consider the data adjustments needed to ensure consistency between the data measurements and the neoclassical model. They include the government capital stock and consumer durables as part of the total capital stock of the economy. We depart from this practice due to data restrictions.

${ }^{5}$ We compare results of two experiments for the US economy: (i) Consumer durables included in consumption and government investment included in governmeny consumption and (ii) Consumer durables included in investment and government investment included in investment except for military investment which is included with government consumption. We obtain very similar results. CKM (2002) also obtain very similar results for different variations on the treatment of data.

${ }^{6}$ The capital output ratio and depreciation output ratio are consistent with our measure of the capital stock (i.e. the net private fixed assets and private inventories).

${ }^{7}$ Results are robust to parameter changes. Changing the value of a calibrated parameter results in changes in the level of various factors, but does not alter the significance of the factors in our accounting exercise. For example, a higher value of $\beta$ relative to the one used in our calibration leads to a higher level of the investment factor but has no effect on the productivity, labor or government factors. A constant shift in the level of the investment factor is unable to alter its importance in accounting for fluctuations in output and other variables. Unlike changes in $\beta$, an increase in the value of $\theta$ affects more than one factor. It leads to downward shifts in the productivity and labor factors, and to an upward shift in the investment factor. However, the importance of the factors in the accounting exercise remains unchanged.
} 


\subsection{Interpretation of the factors}

A detailed presentation of the economic interpretation of the accounting factors is presented in CKM $(2002,2006)$. The accounting factors are essentially reduced forms of concrete distortions in the economy. For example, they stand in for sticky wages, sticky prices or credit market restrictions. Chari, Kehoe, and McGrattan demonstrate that such models are equivalent to a standard neoclassical growth model with different types of time varying factors that distort the equilibrium decisions of economic agents. Some well-known macroeconomic models used for practical purposes feature such frictions. Besides frictions, the time varying factors can also be related to inefficient input utilization of firms, labor income taxes, investment taxes, and government consumption.

\section{Findings}

In this section we report the results of the accounting exercise for Canada for the period 1961 to 2005, as well as for the subperiod 1980 to 2005. We find that for both periods, the movements in output, investment and labor supply in Canada are mainly accounted for by movements in the productivity and labor factors. We find that the government and investment factors play a minor role in both periods considered.

\subsection{The Post 1960 Period}

The findings for the period 1961 to 2005 are reported in Tables 3 and 4 and in Figures 1 through 6 . To summarize, we find that the productivity and labor factors account for most of the movements in output, investment and hours worked in Canada. Examined in isolation, the investment factor yields counterfactual predictions for all three variables. Moreover, the government factor alone plays a small role in accounting for movements in output and investment, but also yields counterfactual predictions for hours worked.

Figure 1 presents Canadian output and the accounting factors. ${ }^{8}$ Recall that in computing the factors we have removed a 2 percent growth trend from the variables that grow with technology, and thus growth is relative to this trend. As seen in Figure 1, output grew by more than trend growth for almost two decades. By 1979 detrended output was 10 percent above its 1961 level. However, the growth slowed down in the next two decades and the current detrended level of output is the same as it was in 1961. In other words, the average growth rate of output per working-age person over the 45 year period was essentially 2 percent, with higher or lower growth in particular

\footnotetext{
${ }^{8}$ We use output to refer to output per working-age person throughout the analysis.
} 
decades. From Figure 1 we also learn that growth in the productivity factor was high for the first 2 decades, but low thereafter. Overall, the productivity factor declined by 8.5 percent throughout the 45 year period. The labor factor, $1-\tau_{l}$, experienced a worsening in the first two decades followed by a subsequent recovery, and it is now at a similar level as in 1961. Over the entire period, the investment factor was reduced in the sense that $\tau_{x}$ declined relative to its 1961 level. The second plot in Figure 1 presents the government factor and net exports as a percent of output. In 1961, the government factor was 20 percent of output. By 2005, it had increased to 26 percent of output. Part of this increase is due to an increase in the net exports' share of output.

We now assess the contributions of the four factors to the movements in output, investment, and labor supply. To this end, we compute model predictions in which some of the factors are permitted to fluctuate, just as measured in the data, while the others are kept constant at their initial levels. Table 3 presents a summary of the results for a number of different models. The models in which only one factor is allowed to fluctuate are labeled "models with one factor". We also consider models in which two or three factors are allowed to fluctuate. The table presents the correlation between data and model predictions for output, investment and hours worked, and gives a rough idea of which factors generate predictions in line with the data. For example, we see that a model in which only the productivity factor is allowed to fluctuate is able to capture a large part of the movements in output, but does not do a good job in capturing fluctuations in hours worked. A model with the labor factor alone captures the movements in hours worked fairly well, while leading to counterfactual predictions for output and investment.

First, we consider the contributions of the productivity factor. In this experiment, the productivity factor is allowed to fluctuate as it does in the data, while the labor, government and investment factors are kept fixed at their 1961 levels. Figures 2, 3 and 4 plot the predictions of the model against data. The prediction for output is in line with data, though the growth predicted is slightly higher in late $1960 \mathrm{~s}$ throughout the late 1970s, and slower from mid $1980 \mathrm{~s}$ until the present. Predicted detrended output in 2005 is 7 percentage points below its 1961 level whereas in the data, detrended output is almost the same in 2005 as it was in 1961. In terms of hours worked, the model is fairly successful at capturing the increasing trend. Over the 45 year period, hours worked increased by 11 percent in the data while the model predicts an increase of 8 percent. In spite of capturing the overall increasing trend, the model with the productivity factor alone does not capture the low level of hours worked observed in the data for the $60 \mathrm{~s}$ and $70 \mathrm{~s}$. In terms of investment, the model predicts much higher investment flows than is seen in the data. 
Next, we consider the contributions of the labor factor. The model with the labor factor alone performs poorly in terms of output and investment. In Figure 2 we see that the model predicts a depression for the Canadian economy for about 20 years followed by a recovery to a level of detrended output very similar to the data. In fact, the predictions of the model for post-1990 are very close to the data. We obtain similar results for investment. The factor factor alone does a better job at capturing the fluctuations in hours worked, although it underpredicts the level of hours.

The last two factors are less successful in capturing fluctuations in output, investment and hours worked. A model with the government factor alone predicts very smooth output, investment and hours worked series. A model with the investment factor alone moves all variables the wrong way, that is when output increases in the data it typically decreases in the model and vice-versa. The same is true for hours worked and investment.

We next examine the predictions of a model with both the productivity and labor factors, since individually these factors proved important in accounting for movements in output and hours, respectively. The results are presented in Figure 5. This model is able to capture fairly well the movements in output and hours worked, but predicts levels of output and hours worked lower than in the data. Figure 5 also shows the predictions of a model in which both the productivity and government factors are allowed to vary. This model is better able to predict the level of output (with the exception of the period from the late $1960 \mathrm{~s}$ to the early 1980s). However, it fails to capture the low hours worked for the early period.

We conclude that a model with both the productivity and labor factors seems to do well in matching the data. Table 4 presents the correlations and root mean squared errors between the model variables and the data for a number of experiments. The table illustrates that output and hours worked as predicted by the model with the productivity and labor factors are, on average, about 9 percent lower than in the data. The root mean squared error for output is a few percentage points higher than in the experiment with the productivity factor alone. However, in that model the prediction for hours worked is at odds with data.

Adding another factor to the productivity and labor factors improves the results. This is not surprising, since by construction a model with all four factors matches the data perfectly. Table 3 presents the results from models including all but one factor. The model labeled "Productivity, labor and government" uncovers the contributions of the three factors by keeping the investment factor fixed at its 1961 level. By comparing this model to the model with the productivity and labor factors alone one can get a sense of how important the government factor is. Similarly, we evaluate 
the importance of the investment factor by comparing the model labeled "Productivity, labor and investment" to the model with the productivity and labor factors alone.

All of the experiments performed lead us to conclude that the forces that manifest themselves as the productivity and the labor factor are critical to an understanding of the movements in output, investment and hours worked over the last 45 years in Canada. Moreover, the investment and government factors play only a minor role.

\subsection{The Growth Slowdown Period}

In this section, we perform an accounting exercise for the growth slowdown period which lasted from 1980 to 2005. The findings are reported in Tables 5 and 6 . The four factors are, by construction, the same as those reported in Figure 1 for the period 1980 to 2005. In fact, the analysis performed from 1980 onward differs from the previous exercise in only one regard: in this exercise the capital stock for the year 1980 is taken as given from data. In the analysis performed for the 45 year period, the capital stock in the year 1980 was determined endogenously in the model and thus was potentially different from the capital stock in the data. Not surprisingly, the results are very similar to those of the previous analysis. The productivity and labor factors together account for most of the fluctuations in output, investment and hours worked, while the contributions of the investment and government factors are small. Indeed the growth slowdown in Canadian output after 1980 is overwelmingly due to a decline in the productivity factor.

In order to gain some perspective on the movements of the productivity and the labor factor outlined in this section, we compare the Canadian experience to that of U.S. The U.S. is chosen as a benchmark economy for two main reasons. Firstly, for the periods considered the United States was the technological leader in the world and thereby defined the technology frontier and potential productivity factor movement. Secondly, the United States is the main trading partner of Canada and therefore they share economically strong bonds. So, if Canada's output per working-age person fell in absolute terms but not relative to the U.S. output per working-age person, then one might think that both countries experienced a similar technological development that is not that extra-ordinary any longer.

Indeed, over the last 45 years, Canadian output per working-age-person has averaged 79 percent of the U.S. level. A big part of this income gap can be accounted for by differences in the productivity factor. In Canada over the same time horizon, the level of TFP has been about 85 percent of the U.S. level (See Figure 7). As a result, about 30 percent of the income difference 
between the U.S. and Canada remain to be accounted for by factors other than productivity, such as inputs into production.

The accounting exercises for both Canada and the U.S. indicate that the productivity and labor factors are key in understanding fluctuations in output, investment and labor supply. To understand how different the two economies are, we compare output and the two factors in Canada and the U.S. over the past 45 years. We find that the correlation between output per workingage-person in the two economies is 60 percent. The productivity factor is much more correlated, at 95 percent, while the labor factors exhibits a correlation of only 78 percent. Figure 8 plots the productivity and labor factors for Canada and the U.S. The labor factor is normalized to 100 in 1961. As we see in the figure, the productivity factors are quite similar between the two economies. This suggests that while the Canadian productivity factor decreased post 1980 it did so in line with the technology leader. On the other hand, the movements in the labor factor have been very different. In the U.S., the forces that manifested themselves as the labor factor have declined significantly starting in 1982. They are now at a much lower level than in 1961. Starting 1982, these forces also declined slightly in Canada however by 2005 they had returned to the same level seen in 1961 . The difference in the labor factor has important implications in the model for labor supply, output and consumption. In particular, we perform a counterfactual experiment for Canada, in which we let the growth in the Canadian labor factor be the same as in the U.S., and keep the other accounting factors as measured from Canadian data. We find that in this experiment growth in output per working-age person per year would have been 0.6 percent higher since the 1980s, allowing Canada to eliminate about half the gap with the U.S. and be only 10 percent below the U.S. by 2005 .

\section{Understanding the Labor Factor in Canada and the U.S.}

To obtain a better understanding of the sources of the labor factor movements, we next consider a model with more tangible distortions in the labor market, and evaluate the degree to which they account for the different movements in the labor factor between the U.S. and Canada.

\subsection{Labor Market Distortions and the Labor Factors in the U.S. and Canada}

The more tangible components of the labor factor, which we consider, are effective labor income taxes, a varying labor income share, and the movement of the gender wage gap. ${ }^{9}$ These factors

\footnotetext{
${ }^{9}$ The factors we introduce using our more tangible model of the labor market are not meant to be exhaustive. This is emphasized by the presence of the residual. We ignored for example the effect of unions, the importance of labor market regulations and the presence of unemployment and a government organized unemployment insurance.
} 
have been suggested in the literature as potential sources of labor factor movements. Specifically, Prescott (2004) analyzed the importance of effective labor income taxes on labor supply. Hansen and Prescott (2005) show that a time varying labor factor captures capital utilization over the business cycle ${ }^{10}$ and can have non-negligible aggregate consequences. Finally, the relationship between the gender wage gap and a time varying labor factor has been shown by Jones et al. (2003). Here the labor factor captures gender wage discrimination in the sense of Goldin (1992) or a lifting of the 'glass ceiling' for women. Here 'glass ceiling' refers to the observation that women have problems advancing in firms beyond a certain level and gender wage discrimination stands for a gap between the wage of a woman relative to the wage of a male despite identical characteristics. The next part presents a stylized model capturing the three components of the labor factor.

\section{Economy with Labor Market Distortions}

There is a representative household, with two members - a male and a female. The household chooses household consumption, $c_{t}$, household investment, $x_{t}$, and hours worked by the male, $l_{m, t}$, and female, $l_{f, t}$, to maximize:

$$
\begin{array}{ll}
P 2(H H) \quad & \max \sum_{t=0}^{\infty} \beta^{t} u\left(c_{t}, l_{m, t}+l_{f, t}\right) N_{t} \\
\text { subject to : } & \\
& c_{t}+x_{t} \leq r_{t} k_{t}+\left(1-\nu_{t}\right)\left(1-\varepsilon_{t}\right)\left(w_{m, t} l_{m, t}+w_{f, t} l_{f, t}\right)+\psi_{t} \\
& \frac{N_{t+1}}{N_{t}} k_{t+1} \leq x_{t}+(1-\delta) k_{t} \\
& l_{m, t} \leq \bar{l}_{t}, k_{0} \text { given }
\end{array}
$$

where $k_{t}$ is the beginning of period capital stock, $r_{t}$ is the rental rate of capital, $w_{m, t}$ and $w_{f, t}$ are the wage rates for males and females respectively, and $\psi_{t}$ are lump-sum household transfers. The working-age population at time $t, N_{t}$, grows at rate $\eta$, hence $N_{t+1}=\eta N_{t}$. Quantity variables are expressed in per working-age-person terms (e.g. $l_{i, t}=\frac{L_{i, t}}{N_{t}}$, where $L_{i}, i \in\{m, f\}$ denotes the total hours worked by males or females).

The hours worked by the male member of the household are constrained from above. For the empirically relevant case $w_{m, t}>w_{f, t}$, this constraint binds in equilibrium. Furthermore, $\nu_{t}$ represents the effective marginal tax rate on labor income ${ }^{11}$ and $\varepsilon_{t}$ is a distortion that is not explicitly

\footnotetext{
${ }^{10}$ It also to some extend captures the changing wage bargaining-power between firms and employees over the business cycle.

${ }^{11}$ Following Prescott (2004), the effective labor income tax, $\nu_{t}$, is computed from data on tax rates as follows:
} 
modeled. The $\varepsilon_{t}$ is meant to stand in for factors other than effective labor income taxes that may distort the marginal rate of substitution between consumption and leisure.

In addition to the representative household, there is a representative firm that has a constant returns to scale technology given by $F\left(K_{t}, \zeta_{t}\left(L_{m, t}+L_{f, t}\right)\right)$. Both male and female labor supplies experience technological progress, at a yearly rate of $\gamma-1$. Hence, $\zeta_{t}=\hat{\zeta}_{t} \gamma^{t}$ where $\gamma^{t}$ is the constant technological progress and $\hat{\zeta}_{t}$ represents deviations from trend growth. Males and females earn different wages. This wage difference is modeled as a cost, $d_{t}>0$, incured when hiring a woman. ${ }^{12}$ As a result women receive only a fraction $\frac{1}{1+d_{t}}$ of the males' wage. Lastly, the CobbDouglas share parameter, $\tilde{\theta}_{t}$, varies exogenously over time. The problem of the representative firm is to maximize profits:

$$
\begin{gathered}
P 2(F): \max F\left(K_{t}, \zeta_{t}\left(L_{m, t}+L_{f, t}\right)\right)-r_{t} K_{t}-w_{m, t} L_{m, t}-\left(1+d_{t}\right) w_{f, t} L_{f, t}, \\
F\left(K_{t}, \zeta_{t}\left(L_{m, t}+L_{f, t}\right)\right)=K_{t}^{\tilde{\theta}_{t}}\left(\zeta_{t}\left(L_{m, t}+L_{f, t}\right)\right)^{1-\tilde{\theta}_{t}}
\end{gathered}
$$

Despite being perfect substitutes in production, male and female hours worked bring different amounts of net income to the household. In other words, male and female hours are taxed differently. From the household budget constraint, we observe that the share of male labor income available to the household is $\left(1-\nu_{t}\right)\left(1-\varepsilon_{t}\right) w_{m, t} l_{m, t}$. In other words, the tax on male labor equals $\nu_{t}+\varepsilon_{t}-\nu_{t} \varepsilon_{t}$. The share of female labor income available to the household is $\left(1-\nu_{t}\right)\left(1-\varepsilon_{t}\right) w_{f, t} l_{f, t}$. This can be also expressed as $\frac{\left(1-\nu_{t}\right)\left(1-\varepsilon_{t}\right)}{\left(1+d_{t}\right)} w_{m, t} l_{f, t}$. Thus, female labor is essentially taxed at a higher rate of: $1-\frac{\left(1-\nu_{t}\right)\left(1-\varepsilon_{t}\right)}{1+d_{t}}$.

Finally, the government balances its budget every period.

$$
\left(g_{t}+\psi_{t}\right) N_{t}=\left(\left[\nu_{t}+\varepsilon_{t}-\nu_{t} \varepsilon_{t}\right] w_{m, t} l_{m, t}+\left[1-\frac{\left(1-\nu_{t}\right)\left(1-\varepsilon_{t}\right)}{1+d_{t}}\right] w_{m, t} l_{f, t}\right) N_{t}
$$

The balanced budget equation above states that the fraction of labor income taxed away is lump-sum rebated to the household after paying for government consumption. Equivalently, the

$\nu_{t}=($ Consumption Tax Rate + Labor Tax Rate $) /(1+$ Consumption Tax Rate $)$. The consumption and labor tax rates as computed following the Mendoza et. al. methodology.

${ }^{12}$ This formulation is agnostic about the reasons for the wage difference. It admits the main two possibilities: (i) gender-productivity differences, (ii) gender-discrimination. One possibility is to think of this as the cost of having a part-time worker compared to a full-time worker. They are equally productive while at work, but part-timers cause extra costs for the employer (set-up cost, administrative (fixed) cost, ...). 
balanced budget equation can also be written as:

$$
\left(g_{t}+\psi_{t}\right) N_{t}=\left(\left[\nu_{t}+\varepsilon_{t}-\nu_{t} \varepsilon_{t}\right] w_{m, t} l_{m, t}+\left[d_{t}-\left(\nu_{t}+\varepsilon_{t}-\nu_{t} \varepsilon_{t}\right)\right] w_{f, t} l_{f, t}\right) N_{t}
$$

Definition 2. A competitive equilibrium is an allocation $\left(c_{t}, x_{t}, k_{t}, l_{m, t}, l_{f, t}, K_{t}, L_{m, t}, L_{f, t}\right)_{t=0}^{\infty}$ and a price system $\left(r_{t}, w_{m, t}, w_{f, t}\right)_{t=0}^{\infty}$ such that:

1. Given the exogenous sequences $\left(\nu_{t}, \varepsilon_{t}, g_{t}, \psi_{t}\right)_{t=0}^{\infty}$ and the prices, $\left(c_{t}, x_{t}, k_{t}, l_{m, t}, l_{f, t}\right)_{t=0}^{\infty}$ solves the household problem, $P 2(H H)$

2. Given the prices, $\left(K_{t}, L_{m, t}, L_{f, t}\right)_{t=0}^{\infty}$ solves the firm's problem, $P 2(F)$

3. The resource constraints are satisfied for all $t$ :

$$
\begin{aligned}
N_{t}\left(c_{t}+x_{t}+g_{t}\right) & \leq F\left(K_{t}, \zeta_{t}\left(L_{m, t}+L_{f, t}\right)\right) \\
K_{t} & \leq N_{t} k_{t} \\
L_{t} & \leq N_{t} l_{m, t}+N_{t} l_{f, t}
\end{aligned}
$$

We detrend all variables that grow over time with technology and denote them by hats (for example, detrended consumption is $\left.\hat{c}_{t}=c_{t} / \gamma^{t}\right)$. Moreover, we use the same functional forms for the utility and production functions as in the earlier model. The equilibrium is characterized by the following first order conditions (for derivation see section A.2):

$$
\begin{aligned}
\frac{u_{2}\left(\hat{c}_{t}, l_{m, t}+l_{f, t}\right)}{u_{1}\left(\hat{c}_{t}, l_{m, t}+l_{f, t}\right)}= & \left(1-\nu_{t}\right)\left(1-\varepsilon_{t}\right) \hat{\zeta}_{t} F_{2}\left(\hat{k}_{t}, \hat{\zeta}_{t}\left(l_{m, t}+l_{f, t}\right)\right) /\left(1+d_{t}\right) \\
\frac{u_{2}\left(c_{t}, l_{m, t}+l_{f, t}\right)}{u_{1}\left(c_{t}, l_{m, t}+l_{f, t}\right)}= & \left(1-\nu_{t}\right)\left(1-\varepsilon_{t}\right) \hat{\zeta}_{t} F_{2}\left(\hat{k}_{t}, \hat{\zeta}_{t}\left(l_{m, t}+l_{f, t}\right)\right)- \\
& -\frac{\mu_{t}}{u_{1}\left(\hat{c}_{t}, l_{m, t}+l_{f, t}\right)} \\
& \left(\text { where } \mu_{t} \geq 0 ; l_{m, t}=\bar{l}_{t} ;\left(\bar{l}_{t}-l_{m, t}\right) \mu_{t}=0\right) \\
\frac{u_{1}\left(\hat{c}_{t}, l_{m, t}+l_{f, t}\right)}{u_{1}\left(\hat{c}_{t+1}, l_{m, t+1}+l_{f, t+1}\right)}= & \beta \gamma^{-\sigma}\left(1-\delta+F_{1}\left(\hat{k}_{t+1}, \hat{\zeta}_{t+1}\left(l_{m, t+1}+l_{f, t+1}\right)\right)\right) \\
\hat{c}_{t}+\hat{x}_{t}+\hat{g}_{t}= & F\left(\hat{k}_{t}, \hat{\zeta}_{t}\left(l_{m, t}+l_{f, t}\right)\right) \\
\eta \gamma \hat{k}_{t+1}= & \hat{x}_{t}+(1-\delta) \hat{k}_{t} \\
\lim _{t \rightarrow \infty}(\beta \eta)^{t} u_{1}\left(\hat{c}_{t}, l_{m, t}+l_{f, t}\right) \hat{k}_{t+1}= & 0
\end{aligned}
$$

Note that the household's budget constraint and the government balance budget equation together yield the resource constraint, hence the two equations are redundant. 
Proposition 1. Let $\left(c_{t}^{*}, x_{t}^{*}, k_{t}^{*}, l_{m, t}^{*}, l_{f, t}^{*}, K_{t}^{*}, L_{m, t}^{*}, L_{f, t}^{*}, r_{t}^{*}, w_{m, t}^{*}, w_{f, t}^{*}\right)_{t=0}^{\infty}$ be a solution to the model with labor market distortions. Define

$$
\begin{aligned}
l_{t}^{*} & \equiv l_{m, t}^{*}+l_{f, t}^{*} \\
L_{t}^{*} & \equiv L_{m, t}^{*}+L_{f, t}^{*} \\
w_{t}^{*} & \equiv \frac{(1-\theta)}{(1-\tilde{\theta})} w_{m, t}^{*}=\frac{(1-\theta)}{(1-\tilde{\theta})} \frac{w_{f, t}^{*}}{1+d_{t}}
\end{aligned}
$$

Moreover, let the productivity factor, $A_{t} \equiv \hat{z}_{t}^{1-\theta}$, the labor factor, $1-\tau_{l, t}$, the government factor, $\tilde{g}_{t}$, and the investment factor, $1 /\left(1+\tau_{x, t}\right)$, from the benchmark model be defined as below.

$$
\begin{gathered}
\hat{z}_{t}^{1-\theta} \equiv \hat{\zeta}_{t}^{1-\tilde{\theta}_{t}}\left(k_{t}^{*}\right)^{\tilde{\theta}_{t}-\theta}\left(l_{t}^{*}\right)^{\theta-\tilde{\theta}_{t}} \\
1-\tau_{l, t} \equiv\left(1-\varepsilon_{t}\right)\left(1-\nu_{t}\right) \frac{\left(1-\tilde{\theta}_{t}\right)}{(1-\theta)}\left(\frac{w_{f, t}^{*}}{w_{m, t}^{*}}\right) \\
\tilde{g}_{t} \equiv g_{t}^{*} \\
(1-\delta)\left(1+\tau_{x, t+1}\right)+\theta \frac{F\left(k_{t+1}^{*}, \hat{z}_{t+1} l_{t+1}^{*}\right)}{k_{t+1}^{*}} \equiv\left(1+\tau_{x, t}\right)\left[1-\delta+F_{1}\left(k_{t+1}^{*}, \hat{\zeta}_{t+1}\left(l_{m, t+1}^{*}+l_{f, t+1}^{*}\right)\right)\right]
\end{gathered}
$$

Then, $\left(c_{t}^{*}, x_{t}^{*}, k_{t}^{*}, l_{t}^{*}, K_{t}^{*}, L_{t}^{*}, r_{t}^{*}, w_{t}^{*}\right)_{t=0}^{\infty}$ are a solution to the benchmark model.

Proof. See Appendix A.3.

Proposition 1. tells us that with $1-\tau_{l, t}$ defined as in (6) the intratemporal conditions in the two models are the same. In the next section we make use of equation (6) to decompose the movements in the labor factor into different components.

\section{Decomposition of the Labor Factors for the U.S. and Canada}

In this section we use equation (6) to decompose the changes in the labor factor, $1-\tau_{l, t}$, into three components and a residual as indicated below.

- an effective labor income tax component: $1-\nu_{t}$, where $\nu_{t}$ denotes the effective labor income tax and captures variations in the labor tax rate and consumption tax rate over time

- a labor share component: $\left(1-\tilde{\theta}_{t}\right) /(1-\theta)$, where $\left(1-\tilde{\theta}_{t}\right)$ denotes the time-varying labor share 
- a gender wage component: $\tilde{w}_{f, t} / \tilde{w}_{m, t}$, that captures for example the changing nature of the labor market due to a decrease in gender wage discrimination

- a residual, $1-\varepsilon_{t}$, computed by using the measured $1-\tau_{l, t}$, as well as data on the three factors:

$$
1-\varepsilon_{t} \equiv\left(1-\tau_{l, t}\right)\left[\left(1-\nu_{t}\right) \frac{\left(1-\tilde{\theta}_{t}\right)}{(1-\theta)}\left(\frac{\tilde{w}_{f, t}}{\tilde{w}_{m, t}}\right)\right]^{-1}
$$

Table 7 presents the decomposition of the labor factor for the U.S. and Canada. We compute the change in the labor factor for each of the economy and see how much of this change can be attributed to the three components considered (i.e. the labor tax, the labor share and the gender wage component) and how much remains unaccounted for (i.e. captured by the residual). We focus on the period since 1970 due to data availability.

As seen in Table 7, the labor factor increased by 18 percent in Canada over the period 1970 to 2005. In other words, the distortions underlying the labor factor have declined. When considered togethered, the three components (i.e. $\left.\left(1-\nu_{t}\right) \frac{\left(1-\tilde{\theta}_{t}\right)}{(1-\theta)}\left[\frac{\tilde{w}_{f, t}}{\tilde{w}_{m, t}}\right]\right)$ increased by only 2.2 percent. Thus only about 13 percent $(\ln (1.022) / \ln (1.18)=0.13)$ of the decrease in distortions can be accounted for by effective taxes, labor share fluctuations and the reduction in the gender wage gap. One interesting observation is that the wage of females in Canada grew dramatically compared to the wage of males throughout the period. This reduction in the gender wage gap contributed to a decline in distortions. However, over the same time period, the effective labor income tax, $\nu_{t}$, increased and the labor share, $1-\tilde{\theta}_{t}$, decreased, both resulting in an increase in distortions that nearly outweighed the contribution of the gender wage component.

Next, we consider the decomposition of the U.S. labor factor. Over the period 1970 to 2005, the labor factor in the U.S. increased more than in Canada. In other words, the labor market distortions in the U.S. declined considerably. About 36 percent of the change in the labor factor can be accounted for by changes in the three factors considered together. Similar to the case of Canada, the wage of females increased considerably more than the wage of males in the U.S. However, the other two components considered decreased. We also perform a decomposition exercise for the U.S. between 1980 and 2005, since most of the increases in the labor factor occured over this period (see Figure 8). As seen in Table 7, the decomposition is more successful for this shorter period, as the changes in the effective labor income tax and labor share components are much smaller compared to the period from 1970 to 2005. In other words, a larger fraction of the labor factor changes in 
the U.S. for the period starting in 1980 are accounted for by reductions in the gender gap. Overall, the three components account for about 57 percent of the changes in the labor factor in the U.S. over the last quarter century. In the case of Canada, an analysis of the 1980 to 2005 period yields similar results as before, because the decline in the effective labor income tax and the labor share components are still large.

We next address the following question: Why have the labor market distortions declined much more in the U.S. compared to Canada over the period 1980 to 2005? We propose a simple experiment based on the decomposition exercise presented above. We want to understand what would the Canadian labor factor be, if Canada were more like the U.S. in some respect. Specifically, we start with equation 6 and compute an implied labor factor for Canada, if Canada had experienced the same changes in the labor share component as the U.S. ${ }^{13}$ In this exercise we leave the other two components and the residual for Canada unchanged. Similarly, we compute implied labor factors for Canada if the Canadian gender gap component changed like that of the U.S., or if Canada had the same effective labor income tax as the U.S. From these experiments we can observe if one of the components is responsible for the different behaviour of the U.S. and the Canadian labor factors. The results are reported in Table 8. The main lesson from this analysis is that if Canada had experienced the same change in its effective labor tax rate as the U.S., the labor market distortions in Canada would have decreased by a lot more. In fact the chage in the labor factor would be very similar to the one observed in the U.S. A small role is played by the gender wage gap differences between the two countries.

We conclude that the reductions in the gender wage gap over the last 35 years contributed somewhat to a reduction in the labor market distortions present in both the Canadian and the U.S. economy. However, other distortions arose over the same period, such as increases in the effective taxes on labor income and decreases in the share of income attributed to labor. The increases in the effective labor income taxes were more pronounced in Canada. Furthermore, a thought experiment based on the decompositon suggests that effective labor taxes account for very large proporiton of the divergence of the labor factors of the two countries.

\footnotetext{
${ }^{13}$ The implied Canadian labor factor if Canada had the US labor share component is calculated as:

$$
\left(1-\varepsilon_{t}^{C A}\right)\left(1-\tau_{l, t}^{C A}\right)\left(\frac{1-\tilde{\theta}_{t}^{U S}}{1-\theta}\right)\left(\frac{w_{f, t}^{C A}}{w_{m, t}^{C A}}\right)
$$
}




\section{Conclusion}

We perform an accounting exercise along the lines outlined in Chari, Kehoe, and McGrattan $(2002,2006)$ for the post-1960 Canadian economy. We consider two time periods; that from 1961 to 2005, as well as the growth slowdown period from 1980 to 2005. For both periods, we find that distortions in the labor-consumption trade-off and the total factor productivity are the key margins that account for most of the changes in output, investment and labor supply. A similar result is derived for the U.S. economy. We compare Canada to the United States. We find that the TFP growth has been similar in the two economies. Moreover, we find a key difference between Canada and the United States to be in the labor factor. In the U.S. the distortions that manifested themselves as labor distortions declined significantly starting in 1980. Labor distortions also decreased in Canada from 1980 to 2005 although to a lesser extent than in the U.S. We decompose these labor distortions into three main components - an effective labor income tax, a labor share and a gender wage component - and a residual. For the U.S., we find that a significant part of the decline in the labor distortions (i.e. about 57 percent), is accounted for by the three factors considered. The reduction in the gender wage gap is particularly important in driving this result. For Canada the three components considered in our decomposition exercise seem less important. The reduction in labor distortions associated with the fall in the gender wage gap observed in Canada is almost entirely wiped out by the increase in the other distortions. We perform a counterfactual experiment that suggests that labor taxes account for a very large part of the divergence in the labor factors of the two nations. 


\section{Appendix}

\section{A.1 Benchmark Model - Equilibrium Conditions}

The Lagrangian for the consumer's problem is given by:

$$
\begin{aligned}
\mathcal{L}=\max \sum_{t=0}^{\infty} & \widetilde{\beta}^{t}\left\{u\left(\hat{c}_{t}, l_{t}\right)\right. \\
& +\vartheta_{t}\left\{\left(1-\tau_{l, t}\right) \hat{w}_{t} l_{t}+r_{t} \hat{k}_{t}+\hat{T}_{t}-\hat{c}_{t}-\left(1+\tau_{x, t}\right) \hat{x}_{t}\right\} \\
& \left.+\xi_{t}\left\{(1-\delta) \hat{k}_{t}+\hat{x}_{t}-\eta \gamma \hat{k}_{t+1}\right\}\right\}
\end{aligned}
$$

where all variables denoted by hat are per working-age person, detrended variables (e.g. $\left.\hat{c}_{t}=c_{t} / \gamma^{t}\right)$. Moreover, $\widetilde{\beta}=\beta \eta h(\gamma)$, and the function $h(\gamma)$ depends on the choice of utility function. For example, if $u\left(c_{t}, l_{t}\right)=\left[\left(c_{t}\left(1-l_{t}\right)^{\alpha}\right)^{1-\sigma}-1\right] /[1-\sigma]$ then $h(\gamma)=\gamma^{1-\sigma}$.

For each time $t$, the first order necessary conditions for the consumer's problem are the budget constraint, the capital stock law of motion, as well as:

$$
\begin{aligned}
u_{1}\left(\hat{c}_{t}, l_{t}\right) & =\vartheta_{t} \\
u_{2}\left(\hat{c}_{t}, l_{t}\right) & =\vartheta_{t}\left(1-\tau_{l, t}\right) \hat{w}_{t} \\
\xi_{t} \eta \gamma & =\widetilde{\beta}\left[\xi_{t+1}(1-\delta)+\vartheta_{t+1} r_{t+1}\right] \\
\xi_{t} & =\vartheta_{t}\left(1+\tau_{x, t}\right)
\end{aligned}
$$

Profit maximization for the firm's problem implies that factor prices satisfy:

$$
\begin{aligned}
r_{t} & =F_{1}\left(\hat{k}_{t}, \hat{z}_{t} l_{t}\right) \\
\hat{w}_{t} & =\hat{z}_{t} F_{2}\left(\hat{k}_{t}, \hat{z}_{t} l_{t}\right)
\end{aligned}
$$

Eliminating the multipliers and the factor prices we obtain the first order conditions presented in the text. 


\section{A.2 Labor Market Distortions Model - Equilibrium Conditions}

The Lagrangian for the household's problem is given by:

$$
\begin{aligned}
\mathcal{L}=\max \sum_{t=0}^{\infty} & (\beta \eta h(\gamma))^{t}\left\{u\left(\hat{c}_{t}, l_{m, t}+l_{f, t}\right)\right. \\
& +\lambda_{t}\left\{r_{t} \hat{k}_{t}+\left(1-\nu_{t}\right)\left(1-\varepsilon_{t}\right)\left(\hat{w}_{m, t} l_{m, t}+\hat{w}_{f, t} l_{f, t}\right)+\hat{\psi}_{t}-\hat{c}_{t}-\eta \gamma \hat{k}_{t+1}+(1-\delta) \hat{k}_{t}\right\} \\
& \left.+\mu_{t}\left\{\bar{l}_{t}-l_{m, t}\right\}\right\}
\end{aligned}
$$

where all variables denoted by hat are per working-age person, detrended variables (e.g. $\left.\hat{c}_{t}=c_{t} / \gamma^{t}\right)$. Moreover, the function $h(\gamma)$ depends on the choice of utility function. For example, if $u\left(c_{t}, l_{t}\right)=\left[\left(c_{t}\left(1-l_{t}\right)^{\alpha}\right)^{1-\sigma}-1\right] /[1-\sigma]$ then $h(\gamma)=\gamma^{1-\sigma}$.

The household's first order necessary conditions are the budget constraint, the capital stock law of motion, as well as:

$$
\begin{aligned}
u_{1}\left(\hat{c}_{t}, l_{m, t}+l_{f, t}\right)= & \lambda_{t} \\
u_{2}\left(\hat{c}_{t}, l_{m, t}+l_{f, t}\right)= & \lambda_{t}\left(1-\nu_{t}\right)\left(1-\varepsilon_{t}\right) \hat{w}_{f, t} \\
u_{2}\left(\hat{c}_{t}, l_{m, t}+l_{f, t}\right)= & \lambda_{t}\left(1-\nu_{t}\right)\left(1-\varepsilon_{t}\right) \hat{w}_{m, t}-\mu_{t} \\
& \left(\mu_{t} \geq 0 ; \bar{l}_{t}-l_{m, t} \geq 0 ; \quad\left(\bar{l}_{t}-l_{m, t}\right) \mu_{t}=0\right) \\
\eta \gamma \lambda_{t}= & \beta \eta h(\gamma) \lambda_{t+1}\left(1-\delta+r_{t+1}\right)
\end{aligned}
$$

Profit maximization for the firm's problem implies that factor prices satisfy:

$$
\begin{aligned}
r_{t} & =F_{1}\left(\hat{k}_{t}, \hat{\zeta}_{t}\left(l_{m, t}+l_{f, t}\right)\right) \\
\hat{w}_{m, t} & =\hat{\zeta}_{t} F_{2}\left(\hat{k}_{t}, \hat{\zeta}_{t}\left(l_{m, t}+l_{f, t}\right)\right) \\
\hat{w}_{f, t} & =\hat{\zeta}_{t} F_{2}\left(\hat{k}_{t}, \hat{\zeta}_{t}\left(l_{m, t}+l_{f, t}\right)\right) /\left(1+d_{t}\right)
\end{aligned}
$$

Eliminating the multipliers and the factor prices we obtain the first order conditions presented in the text.

\section{A.3 Proof of Proposition 1.}

In this section, we prove Proposition 1.

We need to show that the allocations $\left(c_{t}^{*}, x_{t}^{*}, k_{t}^{*}, l_{t}^{*}, K_{t}^{*}, L_{t}^{*}\right)_{t=0}^{\infty}$ and prices $\left(r_{t}^{*}, w_{t}^{*}\right)_{t=0}^{\infty}$ satisfy the first order conditions of the benchmark model, where $l_{t}^{*}, L_{t}^{*}$, and $w_{t}^{*}$ are as defined in Proposition 
1.

\section{Benchmark Model - Equilibrium Conditions}

Let $\left(\tilde{c}_{t}, \tilde{x}_{t}, \tilde{k}_{t}, \tilde{l}_{t}, \tilde{K}_{t}, \tilde{L}_{t}, \tilde{r}_{t}, \tilde{w}_{t}\right)_{t=0}^{\infty}$ be a solution to the benchmark model. Then:

$$
\begin{aligned}
\frac{u_{2}\left(\tilde{c}_{t}, \tilde{l}_{t}\right)}{u_{1}\left(\tilde{c}_{t}, \tilde{l}_{t}\right)} & =\hat{z}_{t} F_{2}\left(\tilde{k}_{t}, \hat{z}_{t} \tilde{l}_{t}\right)\left(1-\tau_{l, t}\right) \\
\frac{u_{1}\left(\tilde{c}_{t}, \tilde{l}_{t}\right)}{u_{1}\left(\tilde{c}_{t+1}, \tilde{l}_{t+1}\right)} & =\frac{\left(1+\tau_{x, t+1}\right)}{\left(1+\tau_{x, t}\right)} \beta \gamma^{-\sigma}\left(1-\delta+\frac{F_{1}\left(\tilde{k}_{t+1}, \hat{z}_{t} \tilde{l}_{t+1}\right)}{\left(1+\tau_{x, t+1}\right)}\right) \\
\tilde{c}_{t}+\tilde{x}_{t}+\tilde{g}_{t} & \leq F\left(\tilde{k}_{t}, \hat{z}_{t} \tilde{l}_{t}\right) \\
\eta \gamma \tilde{k}_{t+1} & =\tilde{x}_{t}+(1-\delta) \tilde{k}_{t} \\
\lim _{t \rightarrow \infty}(\beta \eta)^{t} u_{1}\left(\tilde{c}_{t}, \tilde{l}_{t}\right) \tilde{k}_{t+1} & =0 .
\end{aligned}
$$

\section{Labor Market Distortions Model - Equilibrium Conditions}

Let $\left(c_{t}^{*}, x_{t}^{*}, k_{t}^{*}, l_{m, t}^{*}, l_{f, t}^{*}, K_{t}^{*}, L_{m, t}^{*}, L_{f, t}^{*}, r_{t}^{*}, w_{m, t}^{*}, w_{f, t}^{*}\right)_{t=0}^{\infty}$ be a solution to the labor market distortions model. Then:

$$
\begin{aligned}
\frac{u_{2}\left(c_{t}^{*}, l_{m, t}^{*}+l_{f, t}^{*}\right)}{u_{1}\left(c_{t}^{*}, l_{m, t}^{*}+l_{f, t}^{*}\right)}= & \left(1-\nu_{t}\right)\left(1-\varepsilon_{t}\right) \hat{\zeta}_{t} F_{2}\left(k_{t}^{*}, \hat{\zeta}_{t}\left(l_{m, t}^{*}+l_{f, t}^{*}\right)\right) /\left(1+d_{t}\right) \\
\frac{u_{2}\left(c_{t}^{*}, l_{m, t}^{*}+l_{f, t}^{*}\right)}{u_{1}\left(c_{t}^{*}, l_{m, t}^{*}+l_{f, t}^{*}\right)}= & \left(1-\nu_{t}\right)\left(1-\varepsilon_{t}\right) \hat{\zeta}_{t} F_{2}\left(k_{t}^{*}, \hat{\zeta}_{t}\left(l_{m, t}^{*}+l_{f, t}^{*}\right)\right) \\
& -\frac{\mu_{t}}{u_{1}\left(c_{t}^{*}, l_{m, t}^{*}+l_{f, t}^{*}\right)} \\
\frac{u_{1}\left(c_{t}^{*}, l_{m, t}^{*}+l_{f, t}^{*}\right)}{u_{1}\left(c_{t+1}^{*}, l_{m, t+1}^{*}+l_{f, t+1}^{*}\right)}= & \beta \gamma^{-\sigma}\left(1-\delta+l_{m, t}^{*}=\bar{l}_{t} ;\left(\bar{l}_{t}-l_{m, t}^{*}\right) \mu_{t}=0\right) \\
c_{t}^{*}+x_{t}^{*}+g_{t}^{*} & =F\left(k_{t}^{*}, \hat{\zeta}_{t+1}\left(l_{m, t}^{*}+l_{f, t}^{*}\right)\right) \\
\eta \gamma k_{t+1}^{*}= & x_{t}^{*}+(1-\delta) k_{t}^{*} \\
\lim _{t \rightarrow \infty}(\beta \eta)^{t} u_{1}\left(c_{t}^{*}, l_{m, t}^{*}+l_{f, t}^{*}\right) k_{t+1}^{*}= & 0
\end{aligned}
$$

It is straightforward to see that the law of motion for the capital stock is the same in both economies. Moreover, given the definition of $l_{t}^{*}$ and identical utility functions in the two models, 
the transversality conditions are the same. We are left to show that the star variables satisfy the resource constraint, intratemporal condition and Euler equation of the benchmark model. To do so, we make use of the definitions from Proposition 1.

\section{Resource Constraint}

$$
\begin{aligned}
c_{t}^{*}+x_{t}^{*}+g_{t}^{*} & =F\left(k_{t}^{*}, \hat{\zeta}_{t}\left(l_{m, t}^{*}+l_{f, t}^{*}\right)\right) \\
& =\hat{\zeta}_{t}^{1-\tilde{\theta}_{t}}\left(k_{t}^{*}\right)^{\tilde{\theta}_{t}}\left(l_{m, t}^{*}+l_{f, t}^{*}\right)^{1-\tilde{\theta}_{t}} \\
& =\left[\frac{\hat{z}_{t}^{1-\theta}}{\left(k_{t}^{*}\right)^{\tilde{\theta}_{t}-\theta}\left(l_{t}^{*}\right)^{\theta-\tilde{\theta}_{t}}}\right]\left(k_{t}^{*}\right)^{\tilde{\theta}_{t}}\left(l_{t}^{*}\right)^{1-\tilde{\theta}_{t}} \\
& =\hat{z}_{t}^{1-\theta}\left(k_{t}^{*}\right)^{\theta}\left(l_{t}^{*}\right)^{1-\theta} \\
& =F\left(k_{t}^{*}, \hat{z}_{t} l_{t}^{*}\right)
\end{aligned}
$$

where third equality was derived making use of the definitions of $\hat{z}_{t}^{1-\theta}$ and $l_{t}^{*}$ in Proposition 1.

\section{Intratemporal Condition}

$$
\begin{aligned}
\frac{u_{2}\left(c_{t}^{*}, l_{m, t}^{*}+l_{f, t}^{*}\right)}{u_{1}\left(c_{t}^{*}, l_{m, t}^{*}+l_{f, t}^{*}\right)} & =\left(1-\nu_{t}\right)\left(1-\varepsilon_{t}\right) \hat{\zeta}_{t} F_{2}\left(k_{t}^{*}, \hat{\zeta}_{t}\left(l_{m, t}^{*}+l_{f, t}^{*}\right)\right) /\left(1+d_{t}\right) \\
& =\left[\left(1-\tau_{l, t}\right) \frac{1-\theta}{1-\tilde{\theta}_{t}} \frac{w_{m, t}^{*}}{w_{f, t}^{*}}\right] \hat{\zeta}_{t} F_{2}\left(k_{t}^{*}, \hat{\zeta}_{t}\left(l_{m, t}^{*}+l_{f, t}^{*}\right)\right) /\left(1+d_{t}\right) \\
& =\left(1-\tau_{l, t}\right) \frac{1-\theta}{1-\tilde{\theta}_{t}} w_{m, t}^{*} \\
& =\left(1-\tau_{l, t}\right) w_{t}^{*}
\end{aligned}
$$

where the second equality comes from the definition of $1-\tau_{l, t}$, and the last equality comes from the definition of $w_{t}^{*}$ in Proposition 1. It suffices to show $w_{t}^{*}=\hat{z}_{t} F_{2}\left(k_{t}^{*}, \hat{z}_{t} l_{t}^{*}\right)$ in order to obtain

$$
\frac{u_{2}\left(c_{t}^{*}, l_{t}^{*}\right)}{u_{1}\left(c_{t}^{*}, l_{t}^{*}\right)}=\hat{z}_{t} F_{2}\left(k_{t}^{*}, \hat{z}_{t} l_{t}^{*}\right)\left(1-\tau_{l, t}\right)
$$


Making use of the definitions of $w_{t}^{*}$ and $\hat{z}_{t}^{1-\theta}$ we have

$$
\begin{aligned}
w_{t}^{*} & \equiv \frac{1-\theta}{1-\tilde{\theta}_{t}} w_{m, t}^{*} \\
& =\frac{1-\theta}{1-\tilde{\theta}_{t}}\left(1-\tilde{\theta}_{t}\right) \hat{\zeta}_{t}^{1-\tilde{\theta}_{t}}\left(k_{t}^{*}\right)^{\tilde{\theta}_{t}}\left(l_{t}^{*}\right)^{1-\tilde{\theta}_{t}} \\
& =(1-\theta)\left[\frac{\hat{z}_{t}^{1-\theta}}{\left(k_{t}^{*}\right)^{\tilde{\theta}_{t}-\theta}\left(l_{t}^{*}\right)^{\theta-\tilde{\theta}_{t}}}\right]\left(k_{t}^{*}\right)^{\tilde{\theta}_{t}}\left(l_{t}^{*}\right)^{1-\tilde{\theta}_{t}} \\
& =(1-\theta) \hat{z}_{t}^{1-\theta}\left(k_{t}^{*}\right)^{\theta}\left(l_{t}^{*}\right)^{1-\theta} \\
& =\hat{z}_{t} F_{2}\left(k_{t}^{*}, \hat{z}_{t} l_{t}^{*}\right)
\end{aligned}
$$

\section{Euler equation}

$$
\begin{aligned}
\frac{u_{1}\left(c_{t}^{*}, l_{m, t}^{*}+l_{f, t}^{*}\right)}{u_{1}\left(c_{t+1}^{*}, l_{m, t+1}^{*}+l_{f, t+1}^{*}\right)} & =\beta \gamma^{-\sigma}\left(1-\delta+F_{1}\left(k_{t+1}^{*}, \hat{\zeta}_{t+1}\left(l_{m, t+1}^{*}+l_{f, t+1}^{*}\right)\right)\right) \\
& =\beta \gamma^{-\sigma} \frac{1}{\left(1+\tau_{x, t}\right)}\left((1-\delta)\left(1+\tau_{x, t+1}\right)+\theta \frac{F\left(k_{t+1}^{*}, \hat{z}_{t+1} l_{t+1}^{*}\right)}{k_{t+1}^{*}}\right) \\
\frac{u_{1}\left(c_{t}^{*}, l_{t}^{*}\right)}{u_{1}\left(c_{t+1}^{*}, l_{t+1}^{*}\right)} & =\beta \gamma^{-\sigma} \frac{\left(1+\tau_{x, t+1}\right)}{\left(1+\tau_{x, t}\right)}\left((1-\delta)+\frac{F_{1}\left(k_{t+1}^{*}, \hat{z}_{t+1} l_{t+1}^{*}\right)}{\left(1+\tau_{x, t+1}\right)}\right)
\end{aligned}
$$

where the second equality comes from the equation that defines $\tau_{x, t}$ in Proposition 1.

\section{A.4 Data}

Given data availability for the Canadian economy we make the following assumptions regarding the stock of consumer durables and the government consumption. Firstly, we treat consumer durables as private consumption with the immediate implication that the stock of consumer durables will not be included in the capital stock of the economy. Secondly, we treat all government investment as government consumption and as a result, the depreciation of government capital is removed from both the income and the product side of the accounts. Moreover, the government stock of fixed assets is not included in the capital stock of the economy. In an additional adjustment to the data, we remove the sales taxes from the gross domestic product in order to obtain output at producer prices.

The adjustments made to the data are presented in Table 1. 
Table 1: Adjustments to NIPA Accounts.

\begin{tabular}{|c|c|}
\hline Product & INCOME \\
\hline 1. Private consumption - Sales Taxes & 1. Compensation of employees \\
\hline 2. Gross private domestic investment & 2. Net capital income \\
\hline 3. Net exports & 3. Depreciation of capital \\
\hline 4. Government consumption & - Depreciation of gov. capital \\
\hline + Government Investment & 4. Taxes on production and imports \\
\hline - Depreciation of gov. capital & - Sales Taxes \\
\hline GDP - Sales Taxes & GDP - Sales Taxes \\
\hline - Depreciation of gov. capital & - Depreciation of gov. capit \\
\hline
\end{tabular}

\section{A.4.1 Sources for data}

The main sources of data for Canada are: Statistics Canada for the national accounts, fixed assets and labor data. The main sources of data for U.S. are: Bureau of Economic Analysis for the national accounts, and fixed assets data, as well as Cociuba, Prescott, Ueberfeldt (2007) for the labor data. A detailed description of the data is presented in a separate data appendix. 


\section{References}

Ahearne, A., Finn Kydland, and M.A. Wynne. 2006. "Ireland's Great Depression," Economic and Social Review 37(2), pp. 215-243.

Braun, R. 1993. "How Large Is the Optimal Inflation Tax?" Journal of Monetary Economics 34, pp. 201-214.

Carlstrom, C. and T. Fuerst. 1997. "Agency Costs, Net Worth, and Business Fluctuations: A Computable General Equilibrium Analysis," American Economic Review 87, pp. 893-910.

Chakraborty, S. 2005. "Business Cycle Accounting: How important are technology shocks as a propagation mechanism? Some new evidence from Japan." Macroeconomics Working Paper 0508002.

Chari, V.V., P.J. Kehoe, and E.R. McGrattan. 2002. "Business Cycle Accounting." Federal Reserve Bank of Minneapolis Working Paper 625.

Chari, V.V., P.J. Kehoe, and E.R. McGrattan. 2006. "Business Cycle Accounting." Forthcoming in Econometrica.

Cociuba, S. 2007. Essays on Growth and Development, University of Minnesota, Manuscript, 2007. Cociuba, S., E.C. Prescott, and A. Ueberfeldt. 2005. "U.S. Hours and Productivity Behavior Using CPS Hours Worked Data: 1959-I to 2005-II" Mimeo. Federal Reserve Bank of Minneapolis.

Cooley, T.F. and Edward C. Prescott. 1995. "Economic Growth and Business Cycles", in Frontiers of Business Cycle Research edited by Thomas F. Cooley. Princeton University Press.

Goldin Claudia. 1992. Understanding the Gender Gap: An Economic History of American Women. NBER Series on Long-Term Factors in Economic Development, Oxford University Press.

Hansen, Gary D. and Edward C. Prescott. 2005. "Capacity constraints, asymmetries, and the business cycle", Review of Economic Dynamics, 8(4), pp. 850-865.

Jones, L.E., R.E. Manuelli, and E.R. McGrattan. 2003. "Why Are Married Women Working So Much?" Staff Report 317, Federal Reserve Bank of Minneapolis.

Jorgenson, D.W. (ed.). 2004. Economic Growth in Canada and the United States in the Information Age. Industry Canada Research Mongraph, Industry Canada Research Publication Program. 
Kehoe, T.J. and E.C. Prescott. 2002. "Great Depressions of the 20th Century." Review of Economic Dynamics. 5(1). pp. 1-18.

Kersting, E.K. 2008. "The 1980s Recession in the UK: A Business Cycle Accounting Perspective." Review of Economic Dynamics. 11(1). pp. 179-191.

Lee, F. and J. Tang. 2000. "Productivity levels and international competitiveness between Canadian and U.S. industries." American Economic Review, 90(2), pp. 176-179.

McGrattan, E.R. "The Macroeconomic Effects of Distortionary Taxation," Research Department Discussion Paper 37, Federal Reserve Bank of Minneapolis.

Mendoza, E. G., A. Razin, and L. Tesar. 1994. "Effective Tax Rates in Macroeconomics: CrossCountry Estimates of Tax Rates on Factor Incomes and Consumption." Journal of Monetary Economics 34: 297-323.

Mulligan, C. 2002. "A Century of Labor-Leisure Distortions," Working Paper 8774, National Bureau of Economic Research.

Prescott, E.C. 2004. "Why Do Americans Work So Much More Than Europeans?," Federal Reserve Bank of Minneapolis Quarterly Review, 28(1), pp. 2-13.

Rao, S., J. Tang, and W. Wang. 2004. "What explains the Canada-U.S. TFP gap?" Industry Canada Working Paper 2006-08.

Rao, S., J. Tang, and W. Wang. 2004. "Measuring the Canada-U.S. productivity gap: Industry dimensions." International Productivity Monitor, 9, pp. 3-14.

Rotemberg, J. and M. Woodford. 1999. "The Cyclical Behavior of Prices and Costs," in Handbook of Macroeconomics, ed. by J. Taylor and M. Woodford. Amsterdam: North-Holland.

Schmitz, J. 2005. "What Determines Labor Productivity? Lessons From the Dramatic Recovery of the U.S. and Canadian Iron-Ore Industries Following Their Early 1980s Crisis," Journal of Political Economy 113, pp. 582-625.

Tang, J. and W. Wang. 2005. "Product market competition, skill shortage and productivity: Evidence from Canadian manufacturing firms." Journal of Productivity Analysis, 23, pp. 317-339. 
Ueberfeldt, A. 2006. "Working Time over the 20th Century." Bank of Canada Working Paper 200618.

Table 2: Model Parameters.

\begin{tabular}{lc}
\hline \hline Capital income share & $\theta=0.33$ \\
Depreciation & $\delta=0.042$ \\
Technology growth & $\gamma=1.020$ \\
Discount factor & $\beta=0.976$ \\
Leisure parameter & $\alpha=1.770$ \\
Intertemporal substitution & $\sigma=1.000$ \\
Population growth & $\eta_{U S}=1.013, \eta_{C A}=1.016$ \\
\hline \hline
\end{tabular}


Table 3: Predictions of Models: Canada, 1961-2005

\begin{tabular}{|c|c|c|c|}
\hline & \multicolumn{3}{|c|}{ Correlation with data: $1961-2005$} \\
\hline & Output, $y$ & Investment, $x$ & Hours worked, $l$ \\
\hline \multicolumn{4}{|l|}{ Models With One FACtor } \\
\hline Productivity factor only & 0.95 & 0.73 & 0.28 \\
\hline Labor factor only & -0.26 & -0.06 & 0.80 \\
\hline Government factor only & 0.69 & 0.38 & -0.16 \\
\hline Investment factor only & -0.43 & -0.11 & -0.38 \\
\hline \multicolumn{4}{|l|}{ Models with Two Factors } \\
\hline Productivity and labor & 0.84 & 0.70 & 0.88 \\
\hline Productivity and investment & 0.82 & 0.51 & -0.23 \\
\hline Productivity and government & 0.94 & 0.85 & 0.18 \\
\hline Labor and investment & -0.70 & -0.24 & 0.82 \\
\hline Labor and government & -0.11 & 0.10 & 0.83 \\
\hline \multicolumn{4}{|l|}{ Models with All but One Factor } \\
\hline Labor, investment and government & -0.65 & 0.03 & 0.85 \\
\hline Productivity, investment and government & 0.81 & 0.68 & -0.23 \\
\hline Productivity, labor and investment & 0.96 & 0.87 & 0.98 \\
\hline Productivity, labor and government & 0.92 & 0.71 & 0.91 \\
\hline
\end{tabular}


Table 4: Detailed Predictions of Models: Canada, 1961-2005.

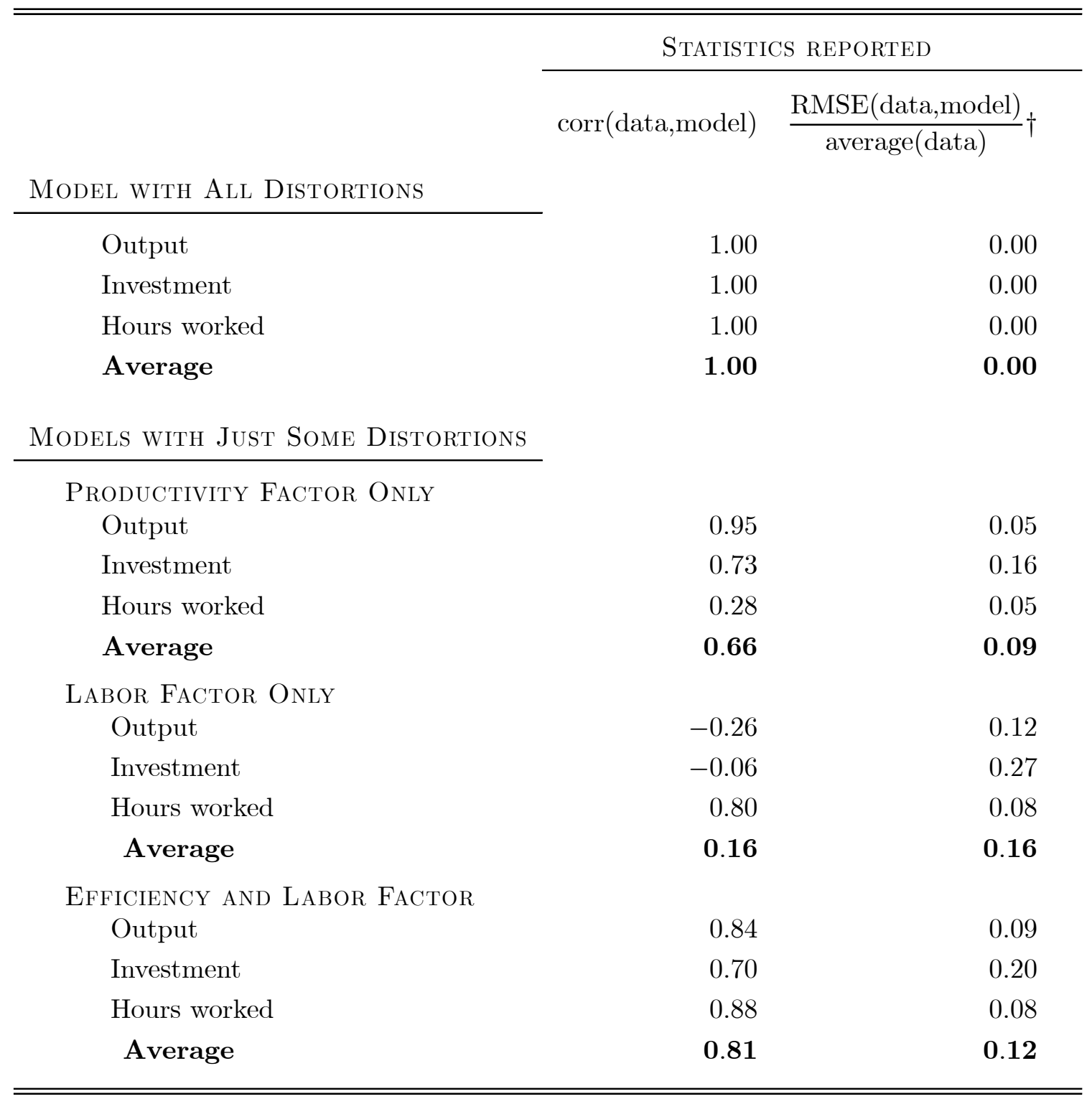

$\dagger$ Following standard definitions the Root-Mean-Square-Error is defined as $\operatorname{RMSE}\left(x_{t}, y_{t}\right)=\left(\frac{1}{T} \sum_{t=1}^{T}\left(x_{t}-y_{t}\right)^{2}\right)^{1 / 2}$ and average $\left(x_{t}\right)=\frac{1}{T} \sum_{t=1}^{T} x_{t}$. 
Table 5: Predictions of Models: Canada, 1980-2005.

\begin{tabular}{|c|c|c|c|}
\hline & \multicolumn{3}{|c|}{ Corelation with data: $1980-2005$} \\
\hline & Output, $y$ & Investment, $x$ & Hours worked, $l$ \\
\hline \multicolumn{4}{|l|}{ Models With One Factor } \\
\hline Productivity factor only & 0.91 & 0.62 & 0.37 \\
\hline Labor factor only & -0.25 & 0.17 & 0.89 \\
\hline Government factor only & 0.64 & 0.09 & -0.15 \\
\hline Investment factor only & 0.06 & -0.22 & -0.60 \\
\hline \multicolumn{4}{|l|}{ Models with Two Factors } \\
\hline Productivity and labor & 0.83 & 0.71 & 0.93 \\
\hline Productivity and investment & 0.79 & 0.39 & -0.42 \\
\hline Productivity and government & 0.90 & 0.75 & 0.18 \\
\hline Labor and investment & -0.40 & 0.02 & 0.82 \\
\hline Labor and government & -0.14 & 0.20 & 0.91 \\
\hline \multicolumn{4}{|l|}{ Models with All but One Factor } \\
\hline Labor, investment and government & -0.28 & 0.09 & 0.84 \\
\hline Productivity, investment and government & 0.79 & 0.50 & -0.48 \\
\hline Productivity, labor and investment & 0.98 & 0.89 & 0.99 \\
\hline Productivity, labor and government & 0.89 & 0.72 & 0.94 \\
\hline
\end{tabular}


Table 6: Detailed Predictions of Models: Canada, 1980-2005.

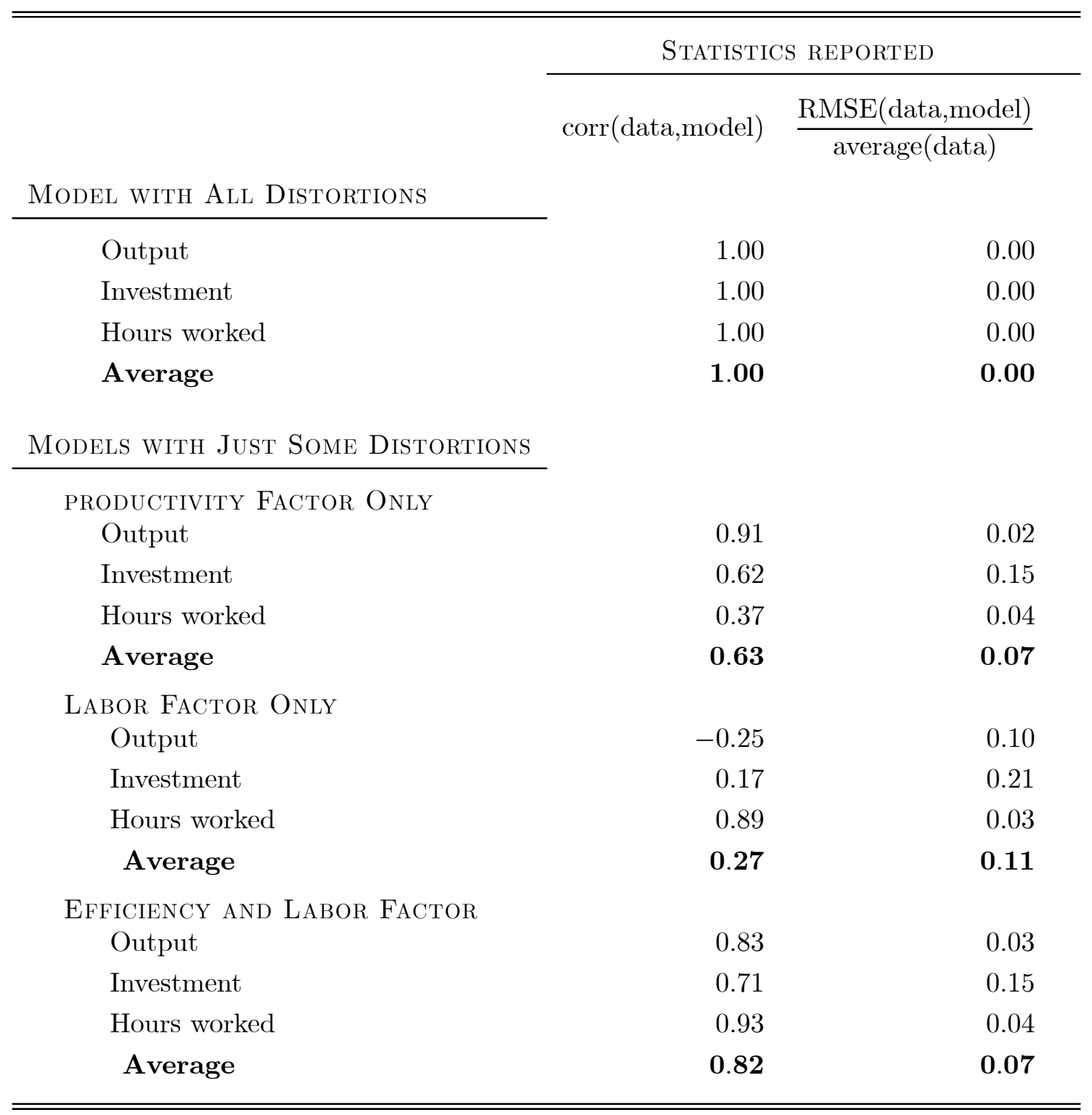


Table 7: Decomposition of Labor Factor.

\begin{tabular}{crrrr}
\hline \hline & \multicolumn{4}{c}{ Growth Factors $\dagger$} \\
& $1970-2005$ & \multicolumn{2}{c}{$1980-2005$} \\
LABOr FACTOR, $1-\tau_{l, t}$ & CANADA & U.S. & CANADA & U.S. \\
Three COMPONENTS & $\mathbf{1 . 1 8 0}$ & $\mathbf{1 . 2 8 4}$ & $\mathbf{1 . 1 0 5}$ & $\mathbf{1 . 2 9 9}$ \\
Effective labor income tax, $1-\nu_{t}$ & $\mathbf{1 . 0 2 2}$ & $\mathbf{1 . 0 9 4}$ & $\mathbf{1 . 0 0 3}$ & $\mathbf{1 . 1 6 1}$ \\
Labor share, $\left(1-\tilde{\theta}_{t}\right) /(1-\theta)$ & 0.85 & 0.91 & 0.86 & 0.97 \\
gender wage component, $w_{f, t} / w_{m, t}$ & 1.34 & 0.94 & 0.98 & 0.97 \\
ReSIDUAL & $\mathbf{1 . 1 5 5}$ & $\mathbf{1 . 1 7 4}$ & $\mathbf{1 . 1 0 2}$ & $\mathbf{1 . 1 1 8}$ \\
\hline \hline
\end{tabular}

$\dagger$ For each variable $v_{t}$, we compute the ratio $v_{2005} / v_{1970}$ or $v_{2005} / v_{1980}$

Table 8: Labor factor differences between U.S. and Canada.

\begin{tabular}{lr}
\hline \hline & $\begin{array}{r}\text { Growth Factor } \\
1980-2005\end{array}$ \\
Actual LABOr FACTORS & 1.299 \\
U.S. & 1.105 \\
CANADA & \\
Implied LABOR FACTOR IF CANADA HAD & 1.097 \\
the U.S. labor share component & 1.152 \\
the U.S. gender wage component & 1.236 \\
the U.S. effective tax component & 1.288 \\
the U.S. effective tax and gender wage components & \\
\hline \hline
\end{tabular}


Figure 1: Canadian Output and the Accounting Factors

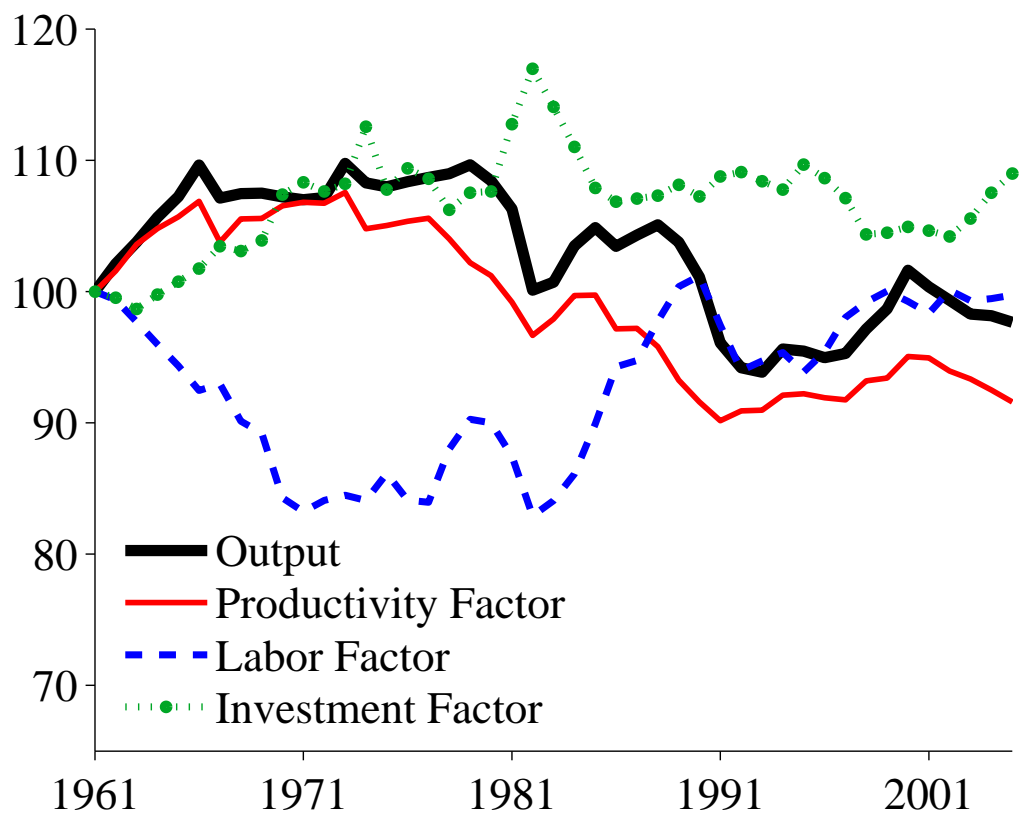

(a) Output and Three Accounting Factors

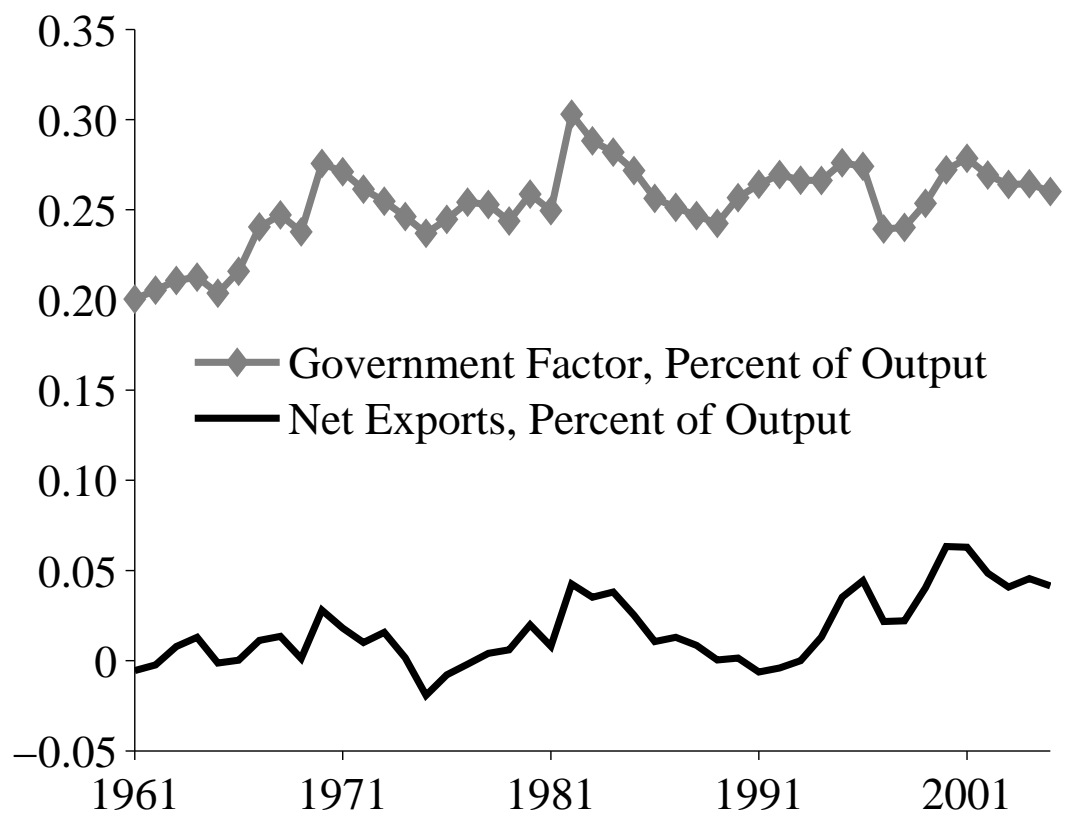

(b) Government Factor and Net Exports, Percent of Output 
Figure 2: Canadian Output: Data and Predictions of Models with One Factor

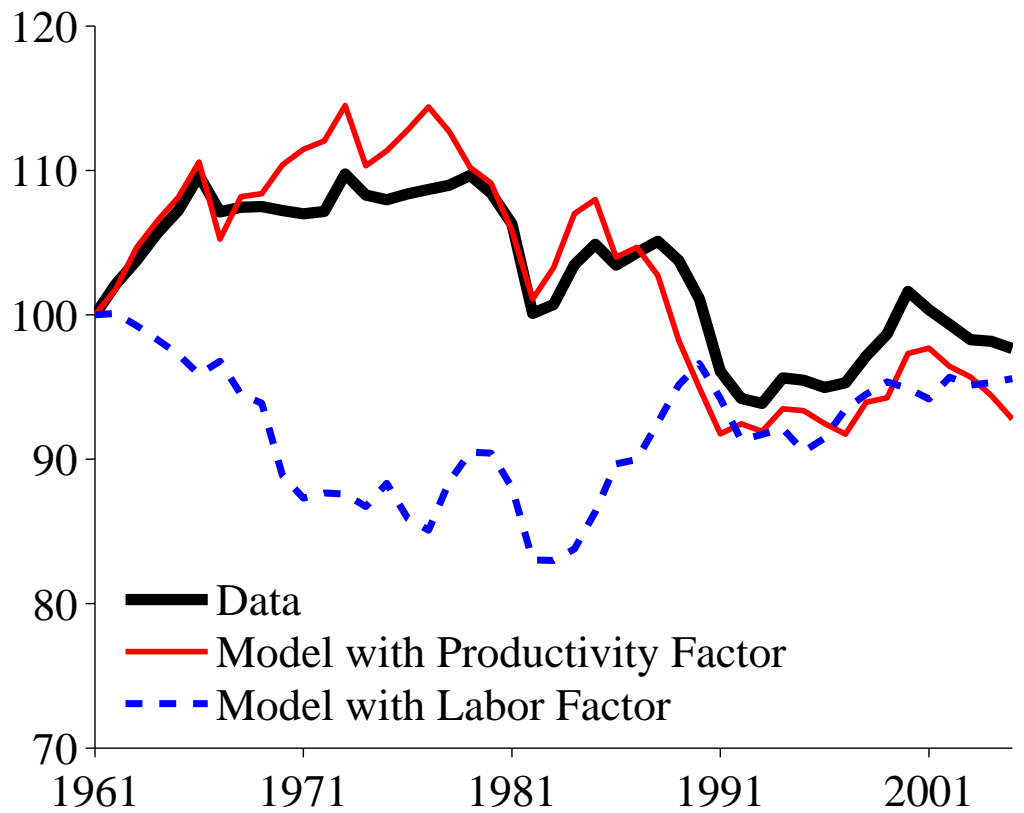

(a)

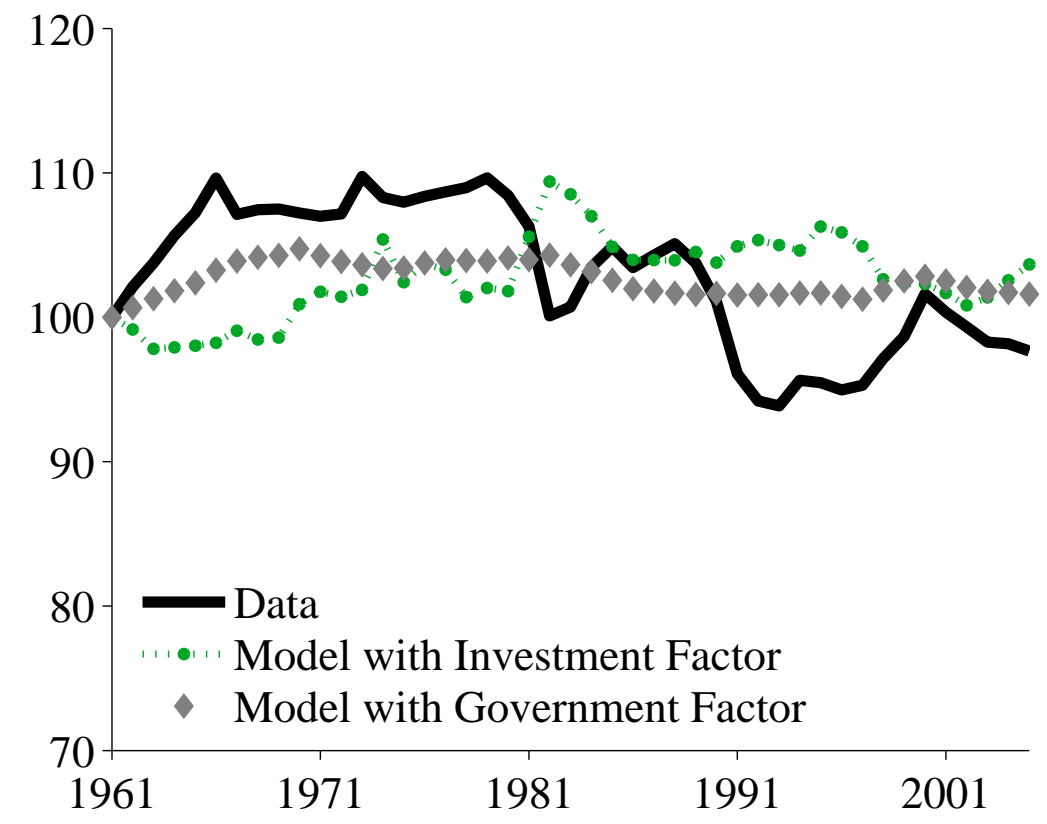

(b) 
Figure 3: Canadian Hours Worked: Data and Predictions of Models with One Factor

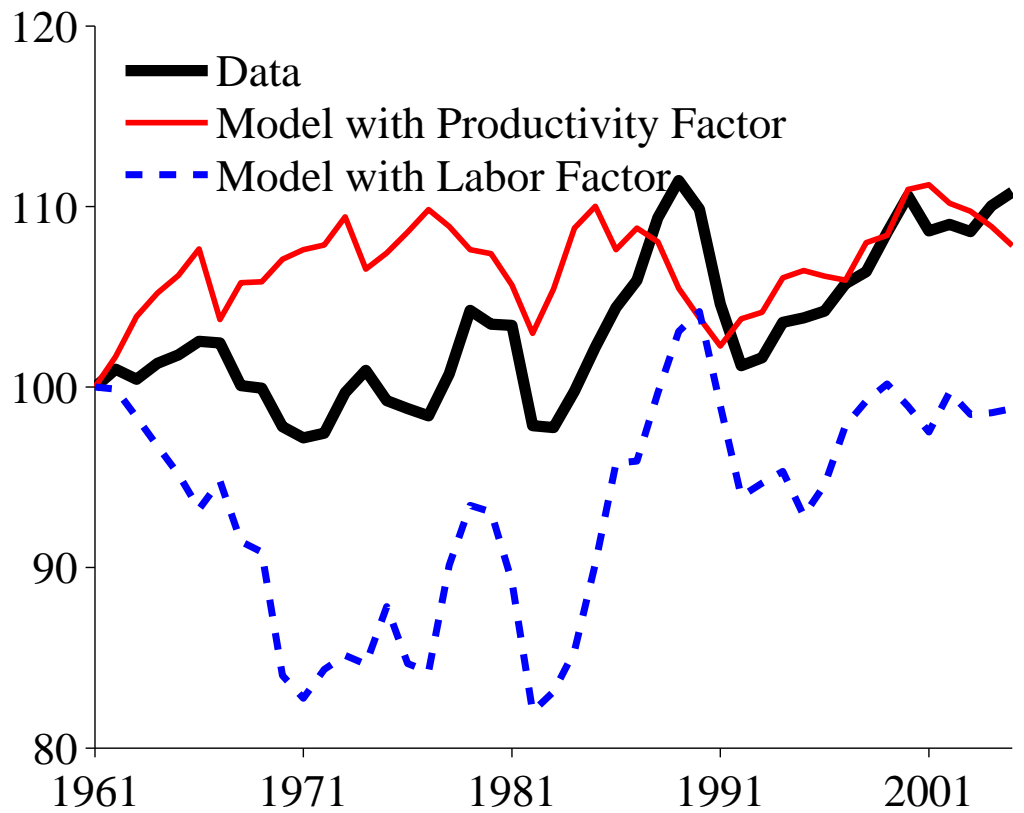

(a)

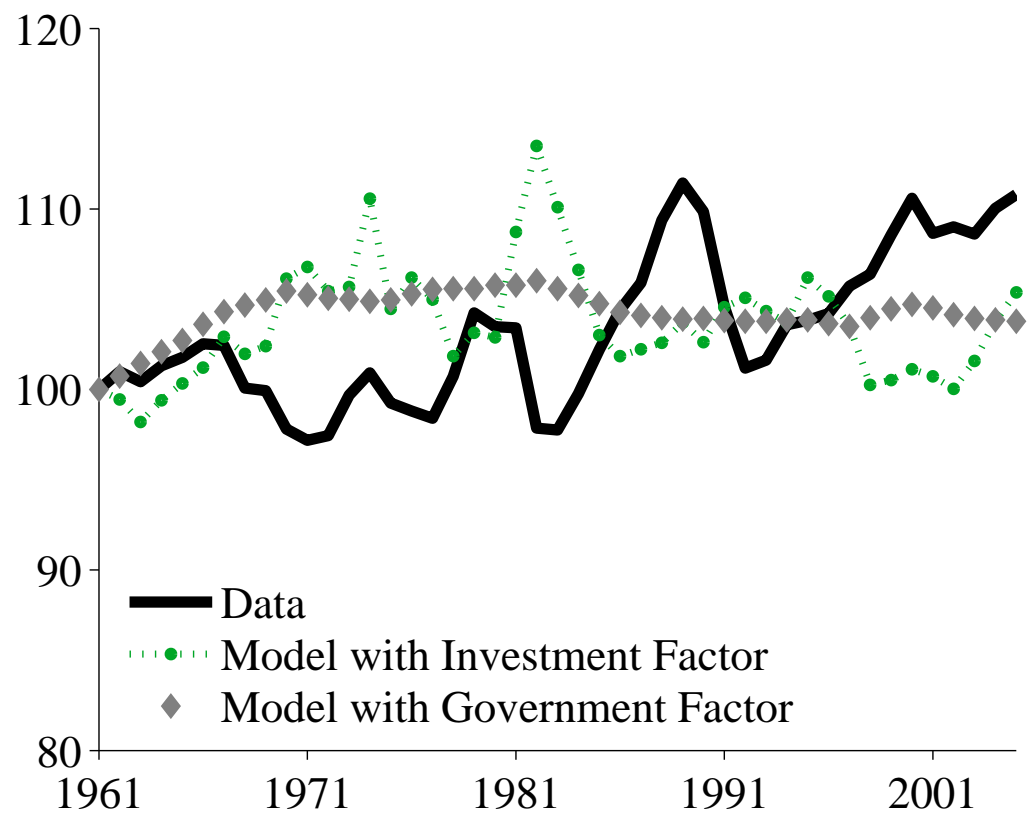

(b) 
Figure 4: Canadian Investment: Data and Predictions of Models with One Factor

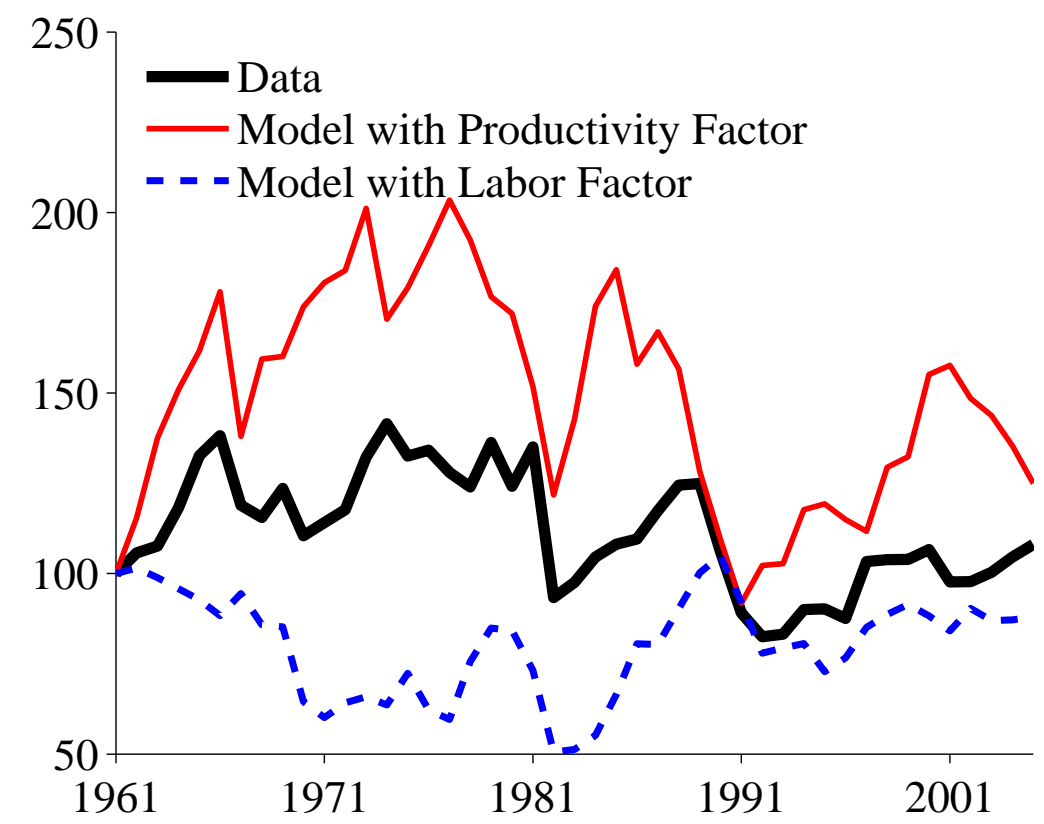

(a)

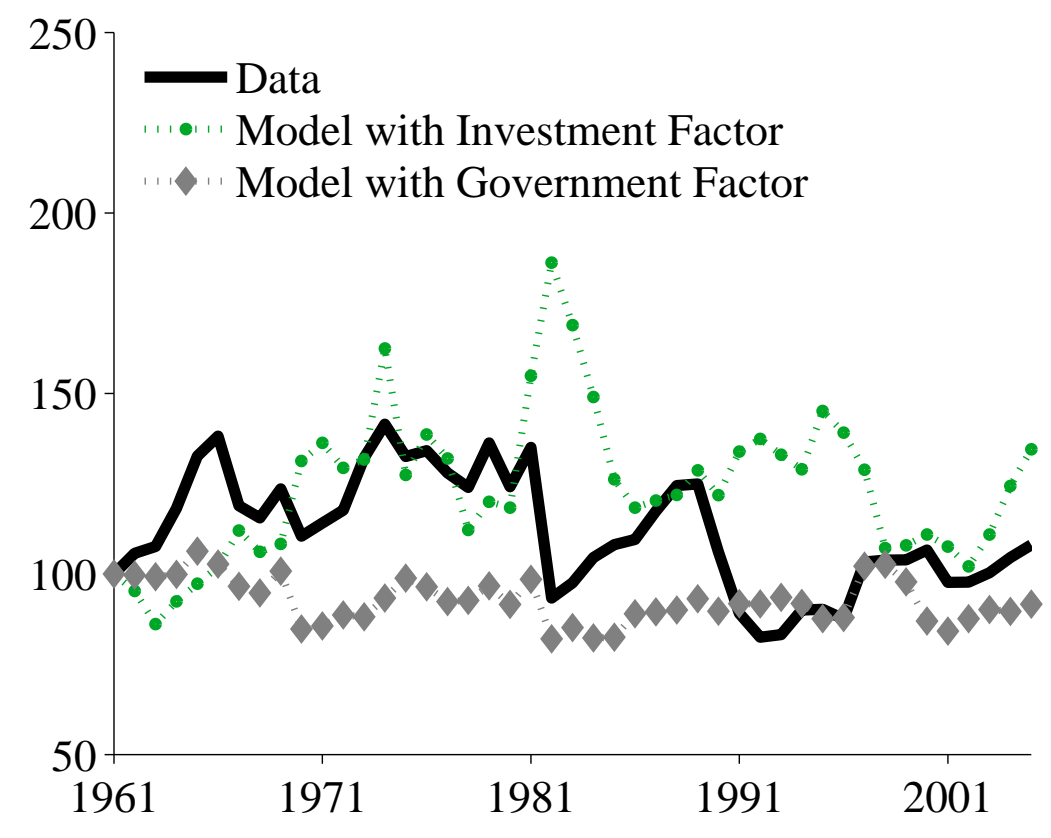

(b) 
Figure 5: Main Factors for Canadian Output and Hours

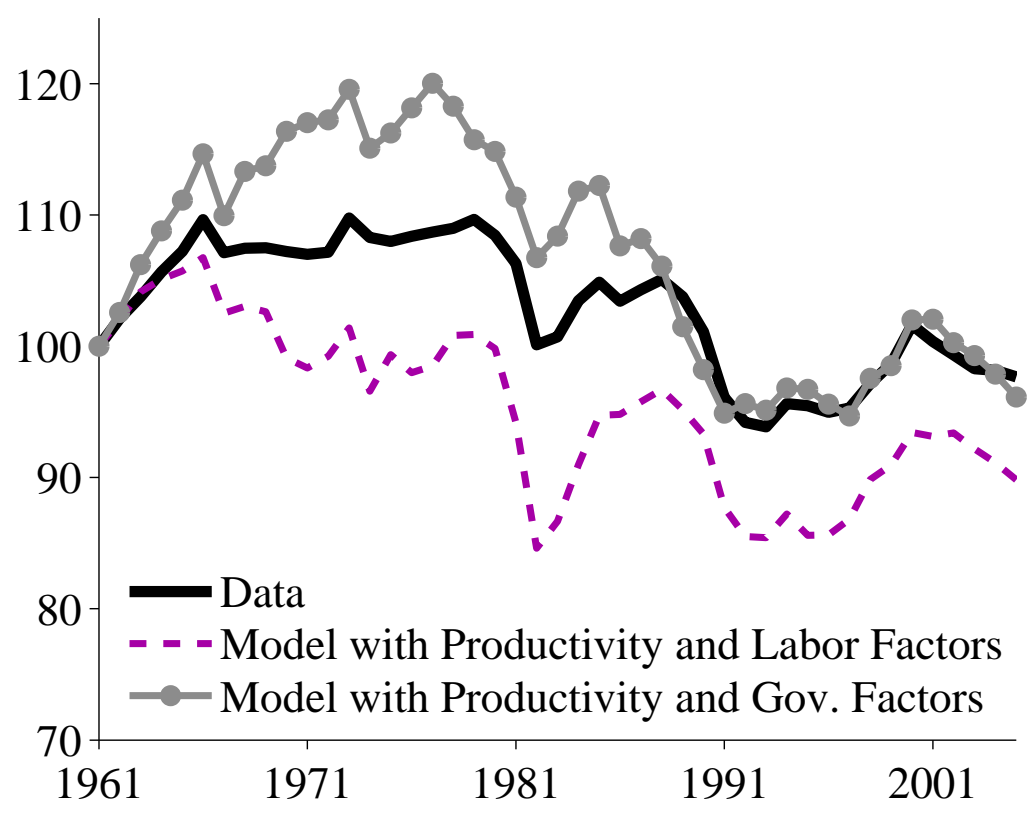

(a) Output: Data and Predictions of Models

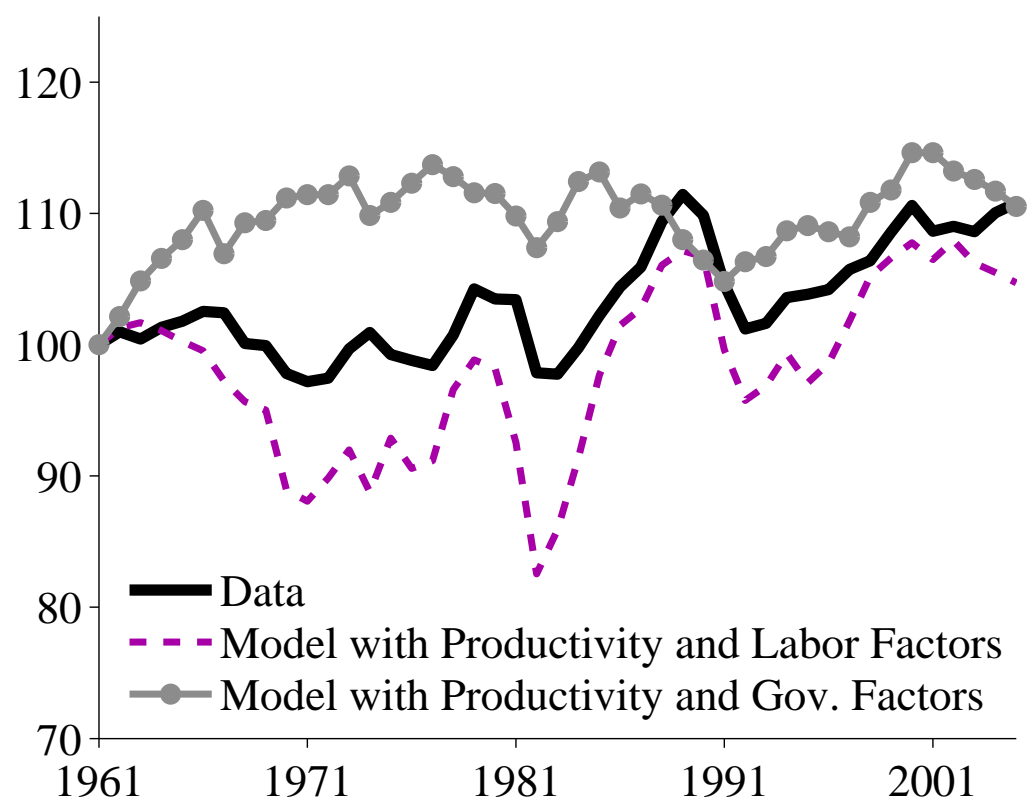

(b) Hours Worked: Data and Predictions of Models 
Figure 6: Canadian Labor Productivity

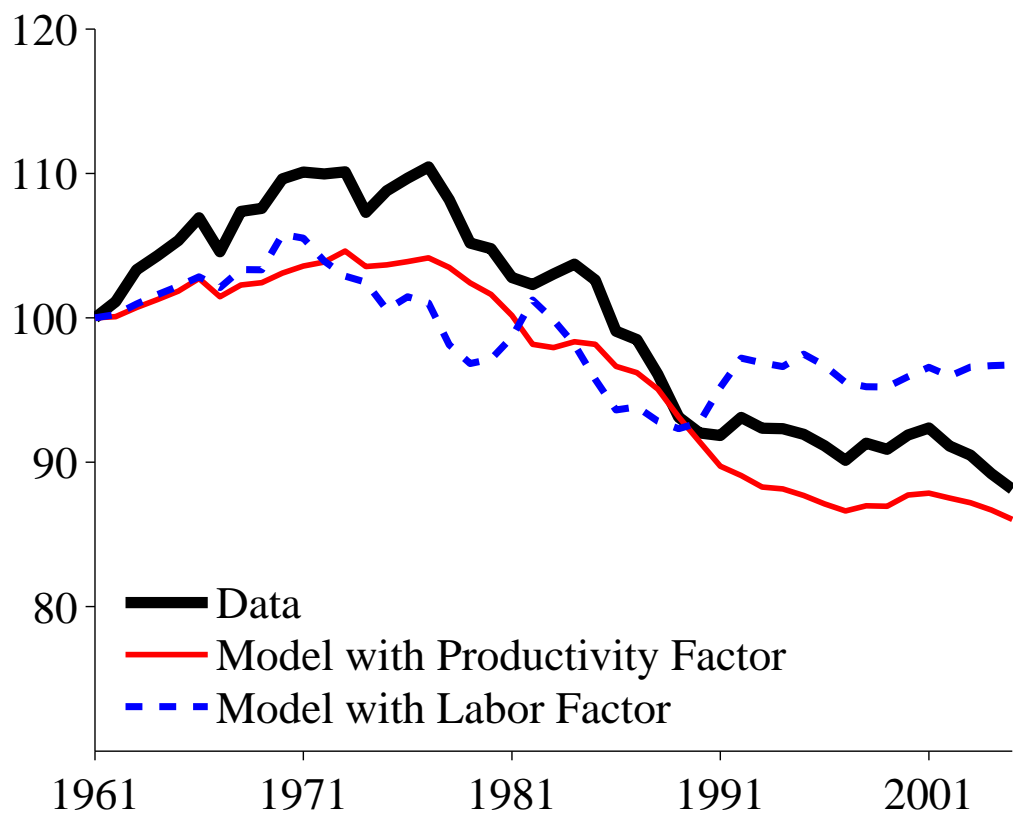

(a) Data and Predictions of Models with One Factor

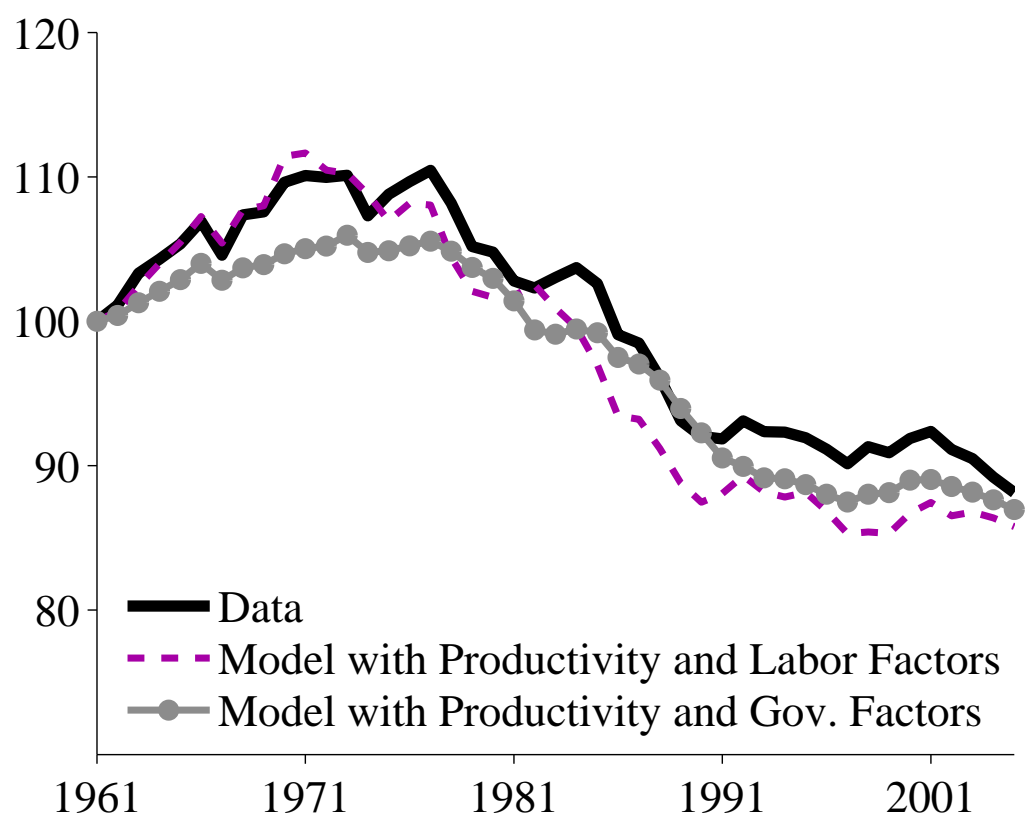

(b) Main Factors for Labor Productivity 
Figure 7: Output and the Productivity Factor in Canada, Percent of US

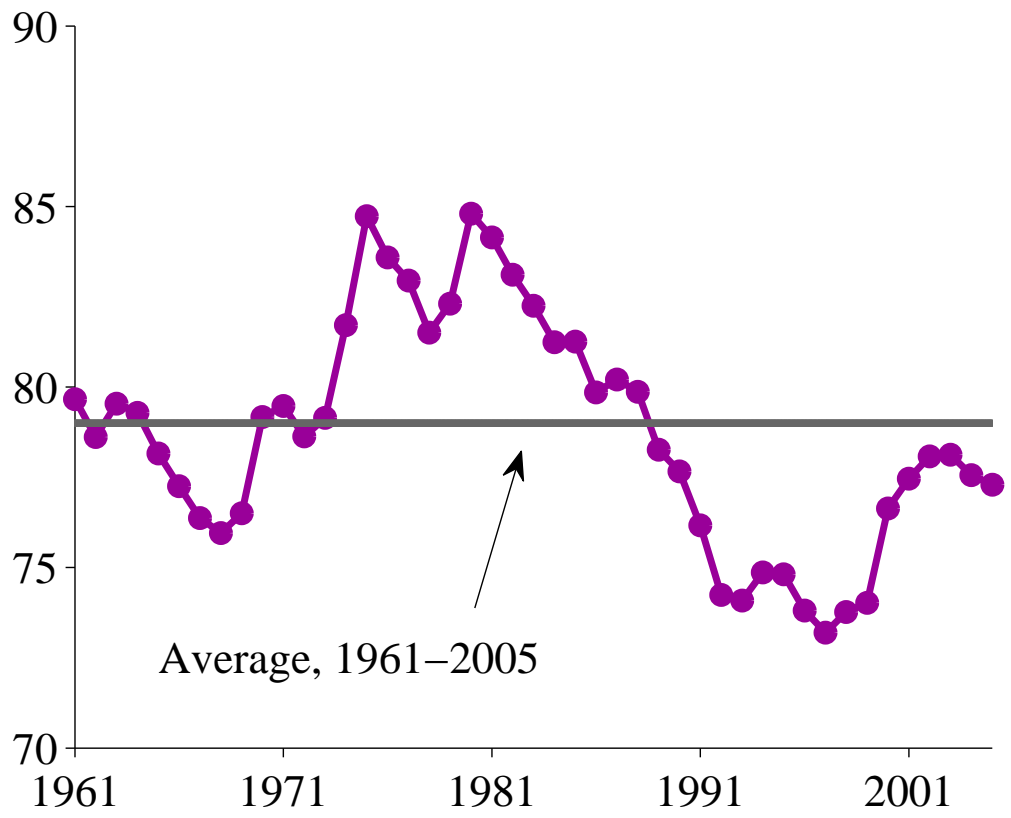

(a) Output per Working-age Person

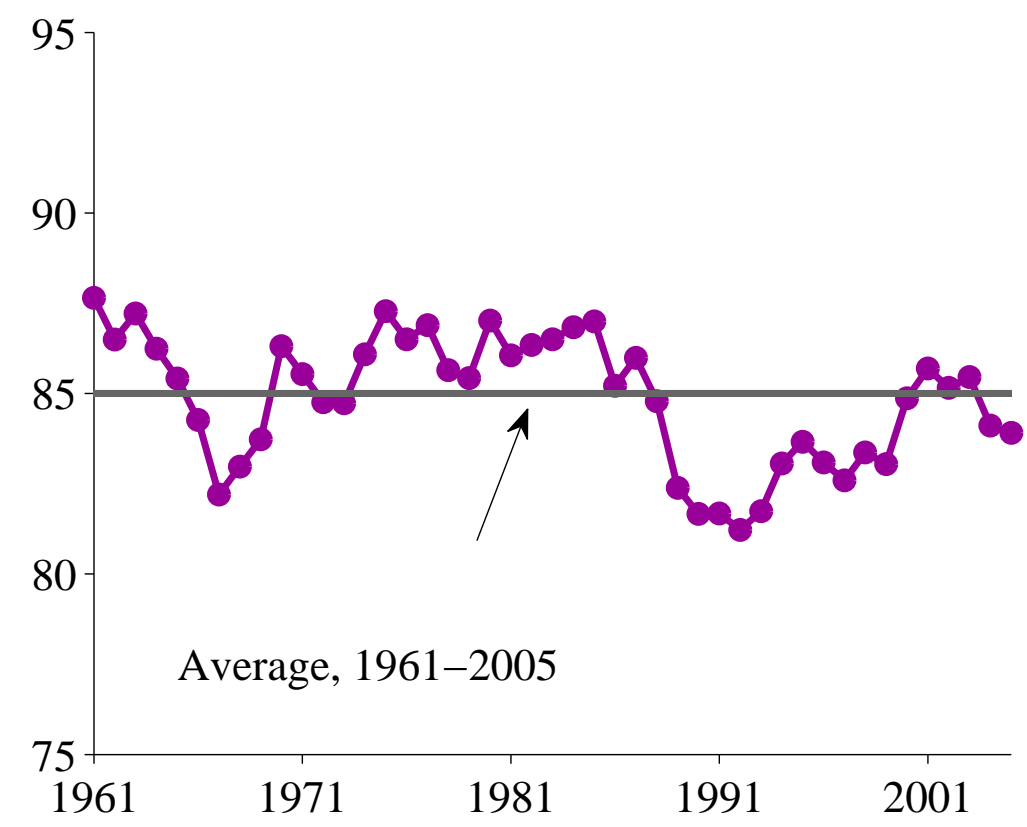

(b) Productivity Factor, $A_{t}$ 
Figure 8: Productivity and Labor Factors in Canada and US

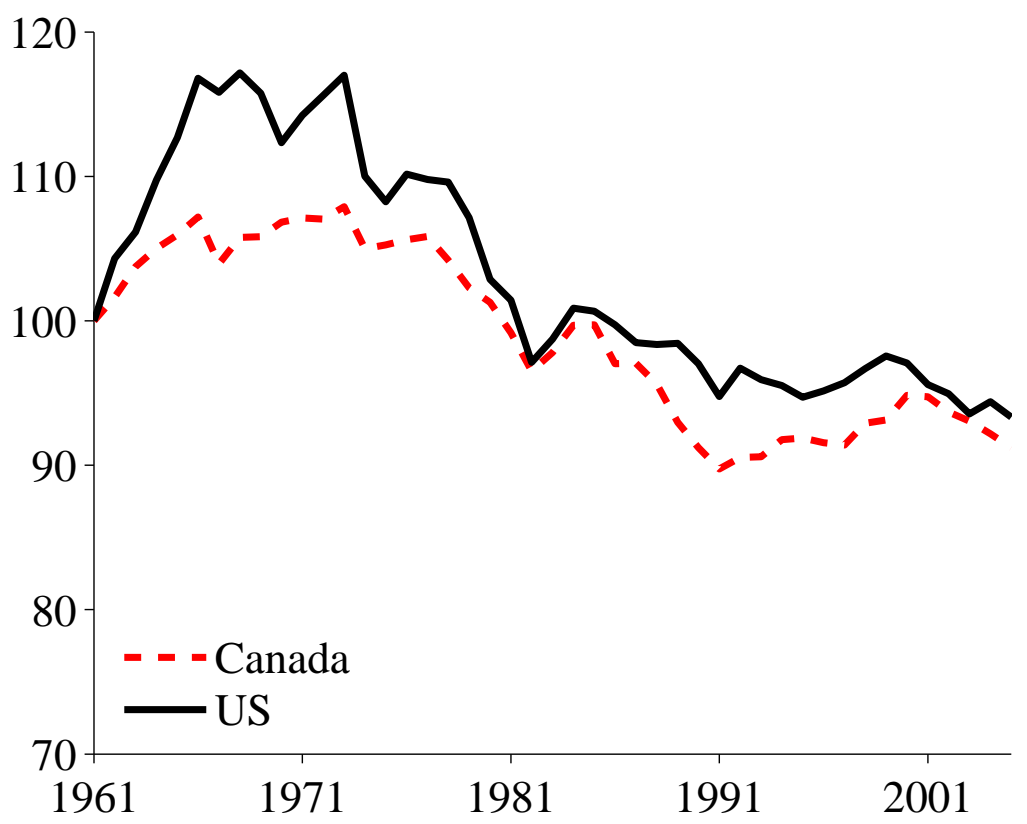

(a) Productivity Factor, $A_{t}$

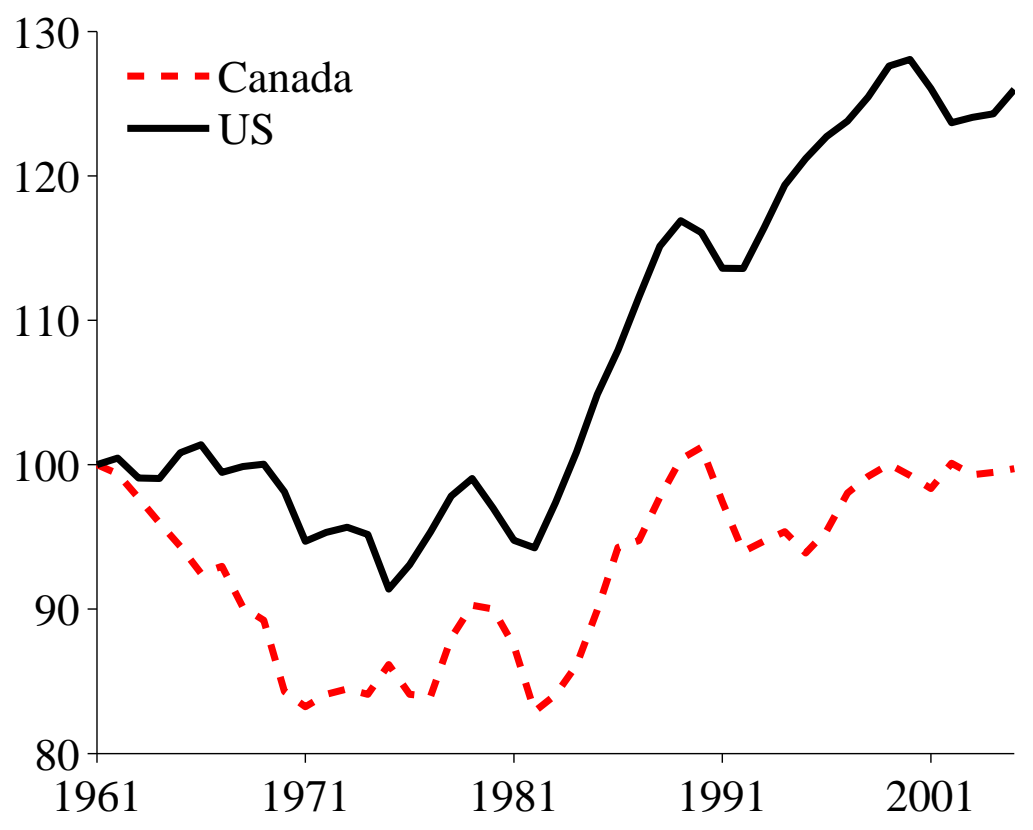

(b) Labor Factor, $1-\tau_{l, t}$ 